\title{
Vorgeschichten und Kontexte
}

Wenn es nun darum geht, das Epos um 1800 als eine alternative Form des Erzählens mit modernespezifischen Funktionen aufzuzeigen, so sind zunächst die ausschlaggebenden Vorläufer und Kontexte der Gattungsentwicklung zu rekonstruieren, bevor die poetologischen Besonderheiten und Erneuerungen der Epochenschwelle überhaupt als solche herausgearbeitet werden können. An die Grundkonstellation eines kritisch auf die Moderne gerichteten EposProjekts soll deshalb im Folgenden über drei dafür als zentral angesehene und aufeinander bezogene Entwicklungsfelder herangeführt werden. Das Epos wird zuerst in seiner gattungspoetologischen Verbindung mit der Antikenrezeption des gesamteuropäischen Klassizismus betrachtet. In der Gegenüberstellung der philologischen Zugriffsversuche auf die Antike von Winckelmann und Wolf zeigt sich nicht nur, wie der Antikenbezug unter den Bedingungen der Moderne zunehmend problematisch wird, sondern können auch die frühen gattungsspezifischen Spannungen zwischen Normativität und Historizität sichtbar gemacht werden, die sich für die Eposkonzepte der Epochenschwelle als ausschlaggebend erweisen werden. Entlang der wirkunsgmächtigen Gattungsexemplare von Klopstock und Wieland zum einen und Goethes Reaktion auf diese Werke zum anderen soll zweitens die Epik des 18. Jahrhunderts als gattungsinterne Vorgeschichte rekonstruiert werden, von der sich die Auseinandersetzung der Jahrhundertwende dann entschieden abheben wird. Dabei wird auch einsehbar werden, inwiefern die Aneignung des Epischen bei Goethe von Anfang an mit reflexiven, kritischen Tendenzen verbunden ist. Schließlich wird ein Blick auf die Französische Revolution als epochales Ereignis der Sattelzeit und die Bedeutung, die ihr von der Goetheforschung zugeschrieben wird, geworfen. Die lange unterhinterfragte Kausal-Verschränkung von Französischer Revolution, Weimarer Klassizismus und der Restitution des Epos soll einer kritischen Revision unterzogen werden, deren Einsichten dann an einer exemplarischen Lektüre von Goethes Reineke Fuchs überprüft werden. 


\section{Antikenbilder und Antikenrezeption}

\subsubsection{Joachim Winckelmann: Homers Epos und die Kulturgeschichte}

Bis in die Barockzeit und auch im späten 19. und 20. Jahrhundert wird der deutschen Antikenaneignung im Vergleich $\mathrm{zu}$ den anderen europäischen Philologien fast keine oder nur marginale Bedeutung zugemessen. In der 2. Hälfte des 18. Jahrhunderts erlangt sie allerdings höchste Aktualität ${ }^{1}$ und nimmt an der Schwelle zum 19. Jahrhundert eine klare Schlüsselfunktion sowohl für die klassizistische wie auch die romantische Tradition ein. Diese bis weit ins 19. Jahrhundert hineinwirkende Antikenbegeisterung des deutschen Kulturraums wird maßgeblich ausgelöst und bestimmt durch Johann Joachim Winckelmanns Frühwerk Gedanken über die Nachahmung der griechischen Werke in der Malerei und der Bildhauerkunst (1755) sowie seine Hauptschrift Geschichte der Kunst des Altertums (1764).

Die darin entwickelte Idealisierung der antiken Kunst, ihre Installation als Norm und das Postulat ihrer Nachahmung schließen durchaus an eine gesamteuropäische neoklassizistische Tendenz an, ${ }^{2}$ deren vorläufiger Höhepunkt wohl die französische Klassik des späten 17. Jahrhunderts markiert. Während sich die französischen und italienischen Klassizisten jedoch vor allem an der römischen Antike orientierten, weicht Winckelmann davon nun entschieden $\mathrm{ab}$ und wendet sich ganz dem antiken Griechenland zu. Hier verortet er ein historisch beispielloses Zusammentreffen der geographischen, klimatischen und politischen Verhältnisse, das die Entwicklung eines vortrefflichen Menschengeschlechts bedingt, dessen Kunst über die blosse Nachahmung der Natur hinausgeht und eine idealische, gleichzeitig vorbildhafte wie uneinholbare Schönheit erreicht. Im Wesentlichen beschreibt Winckelmann damit eine ideale Kulturentwicklung, in der das antike Griechenland und seine spezifischen geographisch-politischen Bedingungen einerseits realer Bezugspunkt sind, zugleich aber mit der mythisch-poetischen Bedeutung einer Wiege der Kultur aufgeladen werden. ${ }^{3}$ Dem Widerspruch zwischen der Einsicht in die Historizität der griechischen Klassik auf der einen und dem Festhalten sowohl an deren Idealstatus wie an einer darauf gerichteten Mimesis-Programmatik

1 Vgl. Riedel, Volker: Antikerezeption in der deutschen Literatur vom RenaissanceHumanismus bis zur Gegenwart. Eine Einführung. Stuttgart: Metzler 200o. S. 4.

2 Vgl. Uhlig, Ludwig: Griechenland als Ideal. Winckelmann und seine Rezeption in Deutschland. Tübingen: Narr 1988. S. 8.

3 Vgl. Winckelmann, Johann Joachim: Gedanken über die Nachahmung der griechischen Werke in der Malerei und Bildhauerkunst (1755). In: Winckelmanns Werke in einem Band, hrsg. v. Helmut Holtzbauer (= Bibliothek deutscher Klassiker). Berlin, Weimar: Aufbau 1969. S. $1-38$, hier S. 1. 
auf der anderen Seite, begegnet Winckelmann zwar mit einer vorwiegend normativen Argumentation, die die problematischen Aspekte der griechischen Gesellschaft - ihre Archaik und ihre undemokratischen Formen ${ }^{4}$ - auszublenden sucht. Und dennoch bleibt seine Antikenbeschreibung im Kern stets der Frage verpflichtet, wie die eigene zeitgenössische Kunst auf einen neuen Höhepunkt gebracht werden kann, ${ }^{5}$ so dass bereits in dieser frühklassizistischen Ausprägung des Antikendialogs Historizität und Normativität ineinander verschränkt sind. ${ }^{6}$

Obwohl Winckelmanns Interesse in erster Linie der bildenden Kunst gilt - zentraler Gegenstand seiner Argumentation ist bekanntlich die LaokoonStatue -, nimmt das Homerische Epos die eigentliche Schlüsselposition in seinem Antikenbild ein. Sämtliches Wissen über die griechische Mythologie, ihre Götter und Helden und schließlich auch das in ihnen verkörperte Menschenbild würde darin überhaupt erst gestiftet: „So viel ist gewiss“, hält Winckelmann in der Vorrede seiner Monumenti antichi inediti fest,

dass nicht nur die Griechen, sondern auch die Römer, seitdem sie an der griechischen Literatur Geschmack fanden, sogar ihre Kinder, ehe sie dieselben in irgend einer andern Wissenschaft unterrichten ließen, zur Lesung des Homerus anhielten, und dieser Dichter wurde von einem jeden, der sich auf die Philosophie oder auf die Kunst der Zeichnung legete [sic], auswendig gelernt. Auf diese Weise wurden seine Gedichte die allgemeine Quelle, aus welcher sowohl die Trauerspieldichter als die Künstler den Stoff zu ihren Werken nahmen, und beide waren versichert, dass dieselben von jedermann, der sie anhörete oder anschauete, verstanden würden. Da die Gedichte Homers ferner mit den übrigen Traditionen der Götterlehre durch das engste Band verknüpft waren, so wurden sie zugleich für ebenso viele die Religion betreffende Nachrichten gehalten, und diese deswegen in den Schulen bei der Lesung dieses Dichters förmlich gelehret. ${ }^{7}$

4 Vgl. Riedel: Antikerezeption in der Deutschen Literatur vom Renaissance-Humanismus bis zur Gegenwart. Eine Einführung. S. 112.

5 Vgl. Kunze, Max: Der „rote Faden“ Winckelmanns - Homer. In: Wiegels, Rainer (Hrsg.): Antike neu entdeckt. Aspekte der Antike-Rezeption im 18. Jahrhundert unter besonderer Berücksichtigung der Osnabrücker Region (= Osnabrücker Forschungen zu Altertum und Antike-Rezeption, Bd. 4). Möhnesee: Bibliopolis 2002. S. 243-251, hier S. 243.

6 Zur aktuellen Winckelmann-Forschung vgl. Disselkamp, Martin; Testa, Fausto (Hrsg.): Winckelmann-Handbuch. Leben - Werk - Wirkung. Stuttgart: Metzler 2017 und Décultot, Élisabeth; Dönike, Martin et al. (Hrsg.): Winckelmann. Moderne Antike. München: Hirmer 2017.

7 Winckelmann, Johann Joachim: Vorrede. In: Johann Winckelmanns sämtliche Werke. Einzige vollständige Ausgabe, hrsg. v. Joseph Eiselein, Bd. 7. Donauöschingen: Verlag deutscher Classiker 1825-1829. S. 24 f. 
Wie sein Griechenlandbild lebt auch Winckelmanns Auffassungen vom Epos und besonders von Homer als poetischem Kulturstifter von einer suggerierten bruchlosen Übereinstimmung von Natur und Ideal. Selbst die „edle Einfalt und stille Größe" ${ }^{8}$ der idealschönen Körper der griechischen Plastiken sieht er in Homers Helden entschieden vorgebildet. ${ }^{9}$ Winckelmanns Erhebung des Homers zum "göttlichen" ${ }^{10}$ Dichter und seines Epos zu der Urquelle der Kunst - um zur "Kenntnis des Schönen zu gelangen“ „betet“ er „Gleichnisse aus dem Homerus"11 - kommt der Installation eines Entstehungsmythos der ganzen abendländischen Kultur gleich. „Ihm schwebt eine Art natürlicher Religion vor", beschreibt Goethe Winckelmanns Intention später in seinem Porträt, „wobei jedoch Gott als Urquell des Schönen und kaum als ein auf den Menschen sonst bezügliches Wesen erscheint ${ }^{\text {“. }}{ }^{2}$ Dadurch wird die Kenntnis der homerischen Epen zur Grundvoraussetzung sowohl für die Kunst der griechischen Klassik wie auch für das spätere Verständnis antiker Darstellungen und Inhalte ${ }^{13}$ - ja, überhaupt für das Entstehen und Entschlüsseln jeglicher Kunst. Die junge Generation der Sturm-und-Drang-Dichter nimmt besonders die an Homer ausgestellte Autorkonzeption enthusiastisch auf und verehrt den antiken Epiker geradezu religiös als Prototyp des Originalgenies. Auch Goethe, der sich sein ganzes Leben über mit Homer beschäftigt, ${ }^{14}$ überhöht den antiken Dichter in seiner Straßburger-Zeit fast maßlos und trägt damit seinen Teil zur Festigung Homers als uneinholbares Muster bei. ${ }^{15}$ Symptomatisch dafür ist das Gedicht Künstlers Morgenlied von 1773, in dem es heißt: „Ich trete vor den Altar hier, / Und lese, wie sich's ziemt, / Andacht liturg'scher Lektion / Im heiligen Homer. ${ }^{46}$ Von der philologisch und historisch

8 Winckelmann: Gedanken über die Nachahmung der griechischen Werke in der Malerei und Bildhauerkunst (1755). S. 1-38, hier S. 23.

9 Vgl. ebd. S. 4.

10 Zitiert nach Wohlleben: Die Sonne Homers. Zehn Kapitel deutscher Homer-Begeisterung. Von Winckelmann bis Schliemann. S. 13 .

11 Zitiert nach ebd. S. 12.

12 Goethe: Winckelmann und sein Jahrhundert. In: Goethe, Johann Wolfgang von: Kunsttheoretische Schriften und Uebersetzungen. Berliner Ausgabe, hrsg. v. Siegfried Seidel, Bd. 19. Berlin: Aufbau 196o ff. S. 480-516, hier S. 510.

13 Vgl. Kunze: Der „rote Faden“ Winckelmanns - Homer. S. 243-251, hier S. 243.

14 Vgl. Jessing, Benedikt: Zwischen Antikisierung und Moderne: Goethes Achilleis. In: Effe, Bernd; Glei, Reinhold F. et al. (Hrsg.): „Homer zweiten Grades“. Zum Wirkungspotenzial eines Klassikers (= Bochumer Altertumswissenschaftliches Colloquium, Bd. 79). Trier: Wissenschaftlicher Verlag Trier 2009. S. 249-264, hier S. 252.

15 Vgl. Meid: Goethes Achilleis - Versuch eines modernen Epos in der Nachfolge Homers. S. 83-101, hier S. $84 \mathrm{f}$.

16 Goethe, Johann Wolfgang von: Poetische Werke. Berliner Ausgabe, hrsg. v. Siegfried Seidel, Bd. 1. Berlin: Aufbau 196o ff. S. 396. 
kritischen Auseinandersetzung mit dem antiken Idol der 179oer Jahre ist diese identifikatorische Vereinnahmung des Homers noch weit entfernt.

In der zweiten Hälfte des 18. Jahrhunderts ist diese Heiligsprechung eines heidnischen Dichters und seine Inszenierung als gottähnlicher Kunstschöpfer ein gleichwohl irritierendes wie konstitutives Moment der Kulturgeschichte. Der Bruch mit der christozentrischen Lehre und ihre Ersetzung durch eine kultische Verehrung der antiken Kunst stellt einen grundsätzlichen Verstoß gegen das gängige Weltbild dar, fügt sich jedoch auch in die einsetzende Glaubensauflösung der Aufklärungszeit. Dies bedeutet sowohl den Beginn der geistigen Revolution, die den deutschen Klassizismus antreibt, wie auch das subsequente Entstehen des kulturellen Vakuums, das den romantischen Synkretismus befördert - die Kunst soll bzw. muss die Religion ersetzen, Pietismus schlägt um in Ästhetik, Glaubensvorstellungen und ihre Wertesysteme werden säkularisiert und auf die Kunst überhaupt, aber in ganz besonderem Maß eben auf die Kunst der Antike übertragen. ${ }^{17}$

Die winckelmannsche Homer-Bearbeitung erhält so einen kaum zu überschätzenden Eigenständigkeitswert für den deutschen Kulturraum, zeigt sich darin doch nicht zuletzt eine ästhetische Gleichursprünglichkeit der Moderne sowohl im Klassizismus wie auch in der Romantik. Denn obwohl die Strömungen unterschiedliche, geradezu komplementäre Lösungsansätze generieren, operieren sie an den gleichen Problemstellungen, die sich allesamt um die Frage „wie weiter?“ drehen. ${ }^{18}$ Dabei beziehen sich beide auf die Kunst der Vergangenheit, genauer die spezifische Neuperspektivierung der griechischen Antike und ihrer Kunst durch Winckelmann. Bezeichnenderweise findet vor Winckelmann in Deutschland keine eigenständige Auseinandersetzung mit Homer statt. Im frühen 18. Jahrhundert werden zwar durchaus Homer-Übertragungen gelesen, die die Ausgangslage für spätere Interpretationsansätze bereitstellen, diese stammen jedoch größtenteils aus England..$^{19}$ Mit der dezidierten Stellungnahme für Homer und für die Griechen wird nun ein neues, unverbrauchtes Prinzip in den zeitgenössischen Kunstdiskurs eingeführt, was sowohl die Initialisierung eines eigenen, deutschen

17 Vgl. Wohlleben: Die Sonne Homers. Zehn Kapitel deutscher Homer-Begeisterung. Von Winckelmann bis Schliemann. S. 13.

18 Vgl. Schneider: Klassizismus und Romantik - zwei Konfigurationen der einen ästhetischen Moderne. Konzeptuelle Überlegungen und neuere Forschungsperspektiven. S. 86-128 und Lubkoll, Christine; Oesterle, Ingrid (Hrsg.): Gewagte Experimente und kühne Konstellationen. Kleists Werk zwischen Klassizismus und Romantik (= Stiftung für Romantikforschung, Bd. 12). Würzburg: Königshausen \& Neumann 2001.

19 Vgl. Wohlleben: Die Sonne Homers. Zehn Kapitel deutscher Homer-Begeisterung. Von Winckelmann bis Schliemann. S. 8. 
Antikendialogs bedeutet als auch eine bewusste Emanzipation von der bisher stark französisch dominierten, auf die römische Tradition fixierte Antikenrezeption. Das Ersetzen der hohen formalen Künstlichkeit der römischen Kunst sowie der Schwülstigkeit des späten Barocks durch eine Ästhetik des Einfachen und Schnörkellosen werden zusammen mit der Übertragung von grundlegenden Überlegungen zur Kunst auf das Feld der Literatur zum deutschspezifischen Signum der Epoche, mehr noch liegt darin sogar eine eigene deutsche Literaturtheorie und -tradition begründet. ${ }^{20}$ Schließlich ist Winckelmann auch deshalb von größter Bedeutung für den deutschen Sprachraum, weil er mit seinem Griechenkult die Vorstellung einer Kunstgeschichte als Kulturgeschichte ${ }^{21}$ einführt, die die Herausbildung des bildungsbürgerlichen Selbstverständnisses einer einzigartigen - sprich eben nur mit den alten Griechen zu vergleichenden -, bedeutsamen Kulturgesellschaft befördert.

\subsubsection{Friedrich August Wolf: Philologische Kritik und die Dekonstruktion des homerischen Epos}

Durch Friedrich August Wolfs Prolegomena ad Homerum erfährt 1795 nicht nur die deutsche Altertumsforschung eine entscheidende Fokusverschiebung, sondern werden auch die Epos-konzeption der Epochenschwelle und ihre besondere Bedeutung für das deutschen Antikenbild wesentlich vorbereitet. Wie alle bisherigen Poetologien greift zwar auch Wolfs Darstellung des homerischen Epos auf die Gattungsüberlieferung zurück und schreibt damit den unhintergehbaren Antikenbezug der Eposdebatte fort, allerdings unterzieht sie das homerische Werk und seine Sonderstellung gleichzeitig einer historisch-philologischen Kritik, die revolutionäre Ergebnisse zutage fördert und darüber hinaus eine grundlegende methodische Erneuerung der wissenschaftlichen Textauslegung bedeutet. Die bis anhin gattungsbestimmende Prämisse der epischen Einheit, die noch auf Aristoteles' Poetik zurückgeht und das hohe Ansehen des Epos mitbegründet, wird nun erstmalig in der deutschen Eposdiskussion hinterfragt. Wolf legt es darauf an, den Status der homerischen Epen zu demontieren, indem er diese als ursprünglich mündlich tradierte, autonome Einzelepisoden darstellt, die erst durch einen langen und gewalthaften Verschriftlichungs- und Kanonisierungsprozess zu den einheitlichen

\footnotetext{
20 Vgl. S. 14 in diesem Buch.

21 Vgl. Keller, Claudia: Lebendiger Abglanz. Goethes Italien-Projekt als Kulturanalyse (= Ästhetik um 1800, hrsg. v. Johannes Grave und Sabine Schneider, Bd. 11). Göttingen: Wallstein 2017. S. 15 o.
} 
Großwerken zusammengefügt wurden, als die sie lange angesehen wurden. ${ }^{22}$ Die kritische Durchsicht der philologischen Homer-Tradition seit der Antike hebt sich sowohl von den vornehmlich ästhetischen Zugriffen der antiken Philologen wie auch von der zeitgenössischen Editionspraxis ${ }^{23}$ entschieden ab und bedeute eine eigentlich archäologische Aufarbeitung nicht nur der Homer zugeschriebenen Texte, sondern des epischen Erzählens überhaupt.

Wolfs Dekonstruktion fusst auf der grundlegenden These, dass die homerischen Epen einer Zeit der rein mündlichen Sänger-Kultur vor der Verschriftlichung der griechischen Sprache entstammten, denn "nicht nur die Dichtungen Homers, sondern auch die des Hesiod u.a., die ganze epische Dichtung, bald auch die lyrische und jambische hat die Kunst der Rhapsoden umfasst; dieselbe ist überhaupt lange die einzige Art, Geisteserzeugnisse zu veröffentlichen $[\ldots]^{“}{ }^{24}$ Die als Schriftwerke überlieferten Epen stellen für Wolf deshalb den Versuch dar, die mündlich tradierten Einzelepisoden zu einer epischen Erzählung zusammenzufügen und gleichwohl die ursprüngliche orale Medialität zu simulieren. Damit siedelt er bereits die antiken Epen an der Schwelle zwischen Poesie und Prosa, Mündlichkeit und Schriftlichkeit an, was sie gleichzeitig traditionell - der mündlich vermittelten Kultur entstammend - und modern - auf die sich durchsetzende Prosaform vorausweisend - erscheinen lässt. Der mediale Wandel des Verschriftlichungsprozesses bedeutet jedoch neben der Konsolidierung des Epischen auch den Verlust wichtiger poetischer Attribute wie Lebendigkeit und Ursprünglichkeit.

Wolf sieht sich deshalb zunächst mit einem Dilemma konfrontiert: Die Haupterkenntnis seiner historisch-kritischen Philologie - dass es keinen eigentlichen Ur-Text, kein Ur-Epos gibt, sondern (nur) eine unabgeschlossene, heterogene Sammlung von variierenden, beliebig kombinierbaren Einzelelementen - spiegelt sich nämlich so gar nicht in der ästhetischen Lektüreerfahrung. Nicht nur sind die homerischen Epen weiterhin populär und lösen auch bei einer ästhetisch und kunstphilosophisch gebildeten Leserschaft nach wie vor Begeisterung aus, ${ }^{25}$ sondern sie präsentieren sich der sinnlichen

22 Vgl. Theisohn, Philipp: Totalität des Mangels. Carl Spitteler und die Geburt des modernen Epos aus der Anschauung (= Epistemata. Reihe Literaturwissenschaft, Bd. 344). Würzburg: Königshausen \& Neumann 2001. S. 18 u. 29.

23 Vgl. ebd.

24 Wolf, Friedrich August: Prolegomena zu Homer, ins Deutsche übertragen von Hermann Muchau, mit einem Vorwort über die Homerische Frage und die wissenschaftlichen Ergebnisse der Ausgrabungen in Troja und Leukas/Ithakas. Leipzig: Reclam 1908. S. 13 o f.

25 Vgl. Osinski, Jutta: Homer-Bilder im 19. Jahrhundert. In: Detering, Heinrich (Hrsg.): Autorschaft. Positionen und Revisionen. Stuttgart: Metzler 2002. S. 202-219, hier S. 203. 
Wahrnehmung auch als einheitliches Ganzes. Wolf nimmt deshalb seinen Befund einer fragmentarischen Disposition des Epischen gerade wieder ein Stück zurück und weicht auf die Antithese von Geist und Buchstabe aus: „Die Homerischen Epen sind nicht so verbildet und verunstaltet, dass sie im einzelnen ein ihrer alten ursprünglichen Form unähnliches Gepräge zeigen. Im Gegenteil passt in ihnen fast alles auf ein und denselben Geist, der darin waltet. ${ }^{\text {26 }}$ Während also die äußere Form philologischer Degeneration zum Opfer fällt, sind im Geist immer noch Ursprünglichkeit und Einheitlichkeit zu beobachten. Wie Matthias Buschmeier zu Recht festgestellt hat, liegt an dieser Stelle „der Wendepunkt, an dem Wolf der kritischen Philologie die hermeneutische Frage nach dem Geist implementiert". ${ }^{47}$ Hier wird nämlich die von Winckelmann postulierte Harmonie von äußerer und innerer Form aufgegeben, dafür wird über den Geistbegriff trotz der materiellen Fragmentarität des Textes an einer inneren Totalität und darüber wiederum an der normativen Geltung der antiken Epen festgehalten. Allerdings gelingt es Wolf damit nicht, die Diskrepanz zwischen kompositorischer Fragmentarität und ästhetischer Ganzheit überzeugend aufzulösen, vielmehr hintertreibt er damit gerade die eigene Argumentation.

Der Hinweis auf den Ursprung der Epen in der Sphäre der Mündlichkeit unterläuft denn auch die Vorstellung von Homers eindeutigen bzw. alleinigen Urheberschaft der Ilias sowie der Odyssee und legt vielmehr eine ursprünglich unbegrenzte Episodenvielfalt sowie das Fehlen einer streng chronologischen Ordnung nahe. Erst durch die späteren redaktionellen Bemühungen der Diaskeuasten ${ }^{28}$ werden die einzelnen Gesänge zu den eigentlichen Konvoluten Illias und Odyssee zusammengefügt. Die Wiederherstellung des „wahren und unverfälschten Text[es], wie er ursprünglich aus seinem [Homers] göttlichen Mund geflossen ist“ ${ }^{29}$, hält Wolf jedoch für grundsätzlich unmöglich. Für ihn ist "Homer" nichts Anderes als eine artifizielle, im Nachhinein auf Einheit und Eindeutigkeit hindrängende Bezeichnung für eine tatsächlich fraktale, plurale

26 Wolf: Prolegomena zu Homer. S. 213.

27 Buschmeier: Epos, Philologie, Roman. Wolf, Friedrich Schlegel und ihre Bedeutung für Goethes Wanderjahre. S. 67.

28 Diaskeuase (griech.): Anordnung, Umarbeitung, Redaktion eines Schriftwerks. Daher war ,Diaskeuasten“ im Altertum der Name derjenigen Gelehrten, welche die Anordnung der Homerischen Gesänge, wie sie seit Peisistratos bestand, einer Revision unterwarfen, einzelne Stücke überarbeiteten und ergänzten, bis jene Gesänge endlich durch die alexandrinischen Grammatiker die jetzige Gestalt erhielten, vgl. Meyers KonversationsLexikon (im Internet seit 2005), Text geprüft am 15.3.2008; publiziert von Peter Hug. https:/peter-hug.ch/lexikon/diaskeuase/w1 [abgerufen am 1.12.2021].

Wolf, Friedrich August: Prolegomena zu Homer. S. 63. 
und daher unklare Überlieferung. ${ }^{30}$ Damit beleuchtet Wolf nicht zuletzt die ganze bisherige Forschungstradition als sowohl unkritische wie unreflektierte Aneignungspraxis ${ }^{31}$ und wendet sich entschieden von ihr ab.

Die Auffassung vom Epos als über die Zeit hinweg entstehendes Kollektivwerk impliziert also auch ein alternatives Autorschaftskonzept, das der damals maßgebenden Vorstellung vom kreativen Originalgenie grundsätzlich entgegensteht. Wolf unterläuft hier nicht nur die Lehre des aus der Genialität des Autors generierten, autonomen Kunstwerks, vielmehr stellt er auch überhaupt die Autorität des Autors so fundamental in Frage wie das erst Roland Barthes für das 20. Jahrhundert in ähnlicher Radikalität wieder tun wird. Nicht etwa Homer sei das Epos zu verdanken, „sondern vielmehr der Kunstfertigkeit eines gebildeten Zeitalters und den vereinten Bemühungen vieler.“32 Es sei die „Tätigkeit des Sammelns und Ordnens“33 der Philologie, die aus Dichtung erst Werke erzeuge ${ }^{34}$ und nicht die Instanz einer Autorperson. Damit wertet er die Editionstätigkeit der antiken Philologen auf, zerschlägt gleichzeitig aber auch die Totalität des antiken Epos und die ganze damit einhergehende Wertund Moralästhetik. ${ }^{35}$ Das als selbstverständlich angenommene Verhältnis von Dichtung und Philologie wird damit relativiert, zumindest in der Antike scheinen Poesie und Wissenschaft in einer integrativen Wechselbeziehung gestanden zu haben. Darüber hinaus erklärt Wolf die Entstehung von Poesie als die spezifische Neigung eines Volkes - der Griechen - zu einem bestimmten Zeitpunkt der Geschichte und leistet damit entscheidende Vorarbeit für die Ausrichtung der Kulturwissenschaften auf Historizität und Nationalität.

Wolfs Auseinandersetzung mit Homer offenbart die epische Form somit als von Anfang an ambivalentes Spannungsfeld homogenisierender und heterogenisierender Kräfte. Formal gesprochen ist das Epos folglich schon immer ein Krisenphänomen, das weder klar begrenzt noch klar strukturiert ist, das immer wieder Bemühungen zur Vervollkommnung und Abgeschlossenheit ausgesetzt ist bzw. diese hervorruft, sich diesen Versuchen aber gerade aufgrund der fragmentarischen Disposition stets widersetzt und ihnen zuwiderläuft. Die Vereinheitlichungsarbeit am Epos erscheint unter diesen Vorzeichen

\footnotetext{
3о Vgl. ebd. S. 136 .

31 Vgl. Buschmeier, Matthias: Epos, Philologie, Roman. Wolf, Friedrich Schlegel und ihre Bedeutung für Goethes Wanderjahre. In: Goethe Jahrbuch 125 (2008). S. 64-79, hier S. 65.

32 Wolf: Prolegomena zu Homer. S. 93.

33 Ebd. S. 166.

34 Vgl. Buschmeier: Epos, Philologie, Roman. Wolf, Friedrich Schlegel und ihre Bedeutung für Goethes Wanderjahre. S. 65 .

35 Vgl. Liggieri: Warum gelingt uns das Epische so selten? Ein Blick hinter Goethes Achilleis. S. 11.
} 
als philologische Abwehrbemühung gegen destabilisierende, die Vorstellung von Ganzheit unterlaufende Tendenzen. Der übergreifende Zusammenhang, die enge Verknüpfung der Episoden zu einem großen Ganzen, dieser durchgehend als gattungsdefinierend behauptete Eindruck von Einheit stellt sich dadurch als Ergebnis einer jahrelangen bewussten Revisions- und Redaktionsbemühung heraus. Demnach scheitert also der Versuch, das Epos formal dingfest zu machen, bereits für die Antike. Alle späteren Bemühungen, die sich auf die vermeintlich gesicherten Merkmale berufen, kommen insofern einer ungeprüften Übernahme von Kriterien gleich, die sich gar nicht aus den Texten selbst ableiten lassen, sondern die schon immer außerliterarisch motivierte Voraussetzungen waren. Es ist aber gerade diese dem Epos schon seit jeher eingeschriebene formale Disparatheit, welche die Bemühung darum so produktiv macht. Nur dank dieser Disposition kann sich das Epos immer wieder aufs Neue als Verhandlungsort und -gegenstand eines politisch motivierten, gesellschaftlich artikulierten Begehrens anbieten und insofern zur Krisenbewältigung auffordern. Besonders deutlich wird diese Funktion jeweils zum Zeitpunkt systemischer Verunsicherung, wie bereits daran ersichtlich wurde, wie Hegels prominente Verabschiedung des Epos gerade die erneute Suche danach, diesmal als Bewältigung einer dekadenten Moderne, forciert.

Für viele Zeitgenossen bedeutet aber die Nivellierung des Homers und die gleichzeitige Aufdeckung des Epos als fragmentarisches, in der Sphäre der Oralität begründetes Gefüge eine fast unerhörte Provokation: „Die gebildete Menschheit war im Tiefsten aufgeregt", beschreibt Goethe die Reaktion auf Wolf später rückblickend, „und wenn sie schon die Gründe des höchst bedeutenden Gegners nicht zu entkräftigen vermochte, so konnte sie doch den alten Sinn und Trieb, sich hier nur eine Quelle zu denken, woher soviel Köstliches entsprungen, nicht ganz bei sich auslöschen. “36 Auch Goethe selbst reagiert im Veröffentlichungsjahr der Prolegomena in einem Brief an Schiller noch unwirsch auf Wolfs Ausführungen, er bezeichnet sie als „subjectiven [sic] Kram“, der ihn „schlecht erbaut" hätte. ${ }^{37}$ In einem Distichon desselben Jahres stellt er schließlich resigniert fest: „Sieben Städte zankten sich darum, ihn [Homer] geboren zu haben, Nun da der Wolf ihn zerriss, nehme sich jede

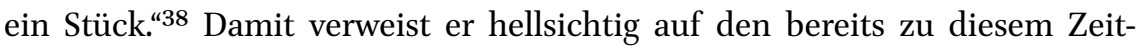
punkt fragwürdig gewordenen, tradierten Kohärenzanspruch an das Epos der griechischen Antike und das gleichzeitige Verfügbarwerden des Epischen für die Gegenwart.

$36 \quad$ WA I, 36. S. $189 \mathrm{f}$.

37 Goethe an Schiller, 17.5.1795, BW. S. 8 o f.

$38 \quad$ MA 4.1. S. 715 . 
Wilhelm von Humboldt findet Wolfs Thesen zwar „vortrefflich gelungen“39, hält seinerseits aber am Totalitätsanspruch des Epos fest, wie sich später zeigen wird. Auch Johann Heinrich Voß beharrt auf der Einheit der Werke sowie der homerischen Autorschaft. ${ }^{40}$ Und selbst Schiller lehnt Wolfs Argumentation konsequent und zeitlebens ab, „der Gedanke an eine Rhapsodische Aneinanderreihung und einen verschiedenen Ursprung“ kommt ihm „notwendig barbarisch“vor, wo die „herrliche Kontinuität und Reciprocität [sic] des Ganzen und seiner Teile“ doch die "wirksamsten Schönheiten“ der Homerischen Gesänge seien. ${ }^{41}$ Friedrich Schlegel gesteht Wolfs Thesen zwar einerseits etwas „Genialisches" zu, aber andererseits hält auch er an der formalen Einheit des Werkes und einer davon nicht ablösbaren Einheit des Urhebers zunächst fest. ${ }^{42}$ Allerdings ist es dann gerade die wolfsche Epos-Dekonstruktion, die Schlegel zu seiner Theorie der inneren Einheit inspiriert. ${ }^{43}$ Diese fast durchgehend ablehnende Haltung gegenüber Wolf hat nicht zuletzt auch damit zu tun, dass zu diesem Zeitpunkt die Idee eines starken, genialischen Dichterindividuums eigentlich noch jung ist und neben Shakespeare gerade auch Homer und Ossian zum Paradigma dieser Vorstellung erhoben worden sind. ${ }^{44}$ Trotz der Skepsis, die ihnen entgegengebracht wird, und unabhängig davon, ob sie die Entstehungsgeschichte der homerischen Epen zutreffend beschreiben, führen Wolfs Thesen unvermeidbar zum Bruch des ästhetischen Antikenbildes nach Winckelmann und der damit verbundenen Idealvorstellung des Epos als Urquell jeglicher Kunst und Kultur.

Der frühe Klassizismus hatte am griechischen Epos, besonders an der Odyssee, im Gegensatz zur kunstvollen Rhetorik der lateinischen Epen das Einfache, Ursprüngliche und Ungekünstelte als erstrebenswert hervorgehoben. In dieser Retrospektive gelang es, den griechischen Kulturraum als ideale, harmonisierte Einheit von Natur und Kunst zu installieren - als Sehnsuchtsort einer Ganzheit, die in der Gegenwart bereits brüchig geworden war. Schillers Emphase der Kontinuität als Merkmal des griechischen Epos und die im Gegenbegriff des Barbarischen aufscheinende Verbindung mit einer

39 Humboldt an Wolf, 30.1.1795. In: Humboldt, Wilhelm von: Briefe an Friedrich August Wolf. Textkrit. hrsg. und komment. Von Philip Mattson. Berlin: Gruyter 199o. S. 111.

40 Vgl. Liggieri: Warum gelingt uns das Epische so selten? Ein Blick hinter Goethes Achilleis. S. 8.

41 Schiller an Goethe, 27.4.1798, BW. S. 638.

42 KFSA III, 23. S. 267 und S. 214. 1796 wird Schlegel seiner Schrift Über die homerische Poesie den Untertitel Mit Rücksicht auf die Wolfischen Untersuchungen hinzufügen.

43 Vgl. Buschmeier: Epos, Philologie, Roman. Wolf, Friedrich Schlegel und ihre Bedeutung für Goethes Wanderjahre. S. $68 \mathrm{f}$.

44 Vgl. Jessing: Zwischen Antikisierung und Moderne: Goethes Achilleis. S. 249-264, hier S. 253 . 
sentimentalischen Kulturvorstellung verdeutlichen diesen Reflex. Die nun mit Wolf einsetzende historisch-kritische Revision des bei Winckelmann und dem jungen Goethe ${ }^{45}$ noch rein ästhetischen Antikenideals hat gravierende Folgen: Werden das Epos und sein genialer Urheber als Inbegriff dieser idealen antiken Kunst dekonstruiert, wird damit auch das ganze Antikenbild fragwürdig bzw. als Konstruktion erkennbar. Oder anders gesagt: Die dem Epos zugeschriebenen Qualitäten von Einheit und Geschlossenheit, Übersicht und Erhabenheit sind keine faktischen Begebenheiten, sondern zeugen tatsächlich von den Defiziten der modernen Gegenwart. Aus dem prekären Jetzt wird ein emphatischer Blick zurückgeworfen und die Kunst der Vergangenheit mit den Verheißungen von Ganzheit und Beständigkeit angefüllt. Diese kritische Dimension, nämlich den gemäß Jacobs in den „romantischen Definitionen der Progressivität von Dichtung konsequent zu Ende gedachten Gedanken, dass es sich bei der Idee der Antike um die Wunschvorstellung einer sentimentalischen, sich selbst überholenden und beschleunigenden Moderne handelt ${ }^{446}$, verdeutlicht Goethe in seiner späteren Winckelmann-Schrift:

Es ist ein gewaltsames Hinreißen in eine von uns nun einmal, sei es auch durch eine notwendige Täuschung, als edler und erhabener angesehene Vergangenheit; eine Gewalt, der selbst, wer wollte, nicht widerstehen kann, [...]. Aber es ist auch nur eine Täuschung, wenn wir selbst Bewohner Athens und Roms zu sein wünschten. Nur aus der Ferne, nur von allem Gemeinen getrennt, nur als vergangen muss das Altertum uns erscheinen. Es geht damit, wie wenigstens mir und einem Freunde mit den Ruinen. Wir haben immer einen Ärger, wenn man eine halb versunkene ausgräbt; es kann höchstens ein Gewinn für die Gelehrsamkeit auf Kosten der Phantasie sein. ${ }^{47}$

Schon erstaunlich bald werden damit die von Winckelmann so wirkungsmächtig initiierte Ablösung Vergils durch den göttlichen Homer als VorzeigeDichter der Antike, die Bevorzugung „stiller Einfalt und edler Größe“48 und die darauf gründende Neuausrichtung der Altertumsforschung auf Griechenland wieder kritisch unterlaufen. ${ }^{49}$ Die Altphilologie überhaupt und die HomerForschung im Speziellen werden dadurch zur Revision gezwungen und das Epos, als Inbegriff der hohen antiken Kunst, rückt endgültig ins Zentrum

\footnotetext{
45 Vgl. S. 41 ff. in diesem Buch.

46 Jacobs, Angelika: Empfindliches Gleichgewicht. Zum Antike-Bild in Goethes Winkelmann und sein Jahrhundert. In: Goethe Jahrbuch (2006). S. 100-114, hier S. 111.

47 MA 6.2. S. 36 of.

48 Winckelmann: Gedanken über die Nachahmung der griechischen Werke in der Malerei und Bildhauerkunst (1755). S. 1-38.

49 Vgl. Christians: Der Traum vom Epos. Romankritik und politische Poetik in Deutschland (1750-2000). S. 22.
} 
dieser nunmehr kritischen Auseinandersetzungen mit der Antike. Dass Wolfs Befunde die revolutionäre Sprengkraft haben, eine grundsätzliche Gattungsdebatte zu initiieren, und nicht als disparate Einzelmeinung diskreditiert werden, verweist darauf, dass über das Epos nicht die vermeintliche Klarheit herrscht. Die philologische Dekonstruktion macht vielmehr deutlich, wie stark das Epos ideologisch aufgeladen ist, wie die Debatte darüber jeweils die zeitgenössischen politischen und kulturellen Auseinandersetzungen abbildet und sich daraus Implikationen ableiten lassen, die weit über den reinen Gattungsdiskurs hinausreichen.

Darüber hinaus gereicht dieser Umstand gerade auch zum Zeichen einer unhintergehbaren Einsicht in die Konstruiertheit normativer Gattungskonzepte. Nun, da das alles bestimmende Kriterium der Einheit verdächtig geworden ist, bringt die Frage nach der eigentlichen, wahren Form des Epos die gattungspoetisch interessierten Zeitgenossen zwar in Schwierigkeiten, eröffnet ihnen aber auch unerwartete Möglichkeiten: „Mit hartherz'ger Kritik hast du den Dichter entleibet", tadelt Goethe Wolf und gesteht ihm gleichwohl zu: „aber unsterblich durch dich lebt das verjüngte Gedicht“ ${ }^{.50}$ Auch bei der späteren Parallellektüre von Homer und Wolf gehen ihm „die wunderbarsten Lichter auf, worüber wir [Goethe und Schiller] künftig gar manches werden zu sprechen haben“. ${ }^{51}$ Dass Goethe innerhalb von zwei Jahren eine völlig veränderte Einstellung zu Wolfs Thesen einnimmt, kann als Hinweis darauf gelesen werden, dass Goethe hier wohl, trotz aller Skepsis gegenüber Wolfs Vorgehen, Anschlussmöglichkeiten für seine eigenen Überlegungen zum Epischen erkennt. Die folgenden Zeilen der dem gleichnamigen Epos vorausgehenden Elegie Hermann und Dorothea des Jahres 1796 bringen dann die volle Tragweite des ambivalenten Verhältnisses zu Wolf zum Ausdruck:

Erst die Gesundheit des Mannes, der, endlich vom Namen Homeros Kühn uns befreiend, uns auch ruft in die vollere Bahn.

Denn wer wagte mit Göttern den Kampf? und wer mit dem Einen?

Doch Homeride zu sein, auch nur als letzter, ist schön.

Darum höret das neuste Gedicht! Noch einmal getrunken!52

Homers Status als göttlicher Dichter wird hier als Hemmschwelle beleuchtet, die eine produktive Aneignung seiner Werke erschwert, wenn nicht sogar ganz verunmöglicht. Durch Wolfs Relativierung der historischen Person Homers und vor allem seiner Autorschaft eröffnen sich den modernen Epikern auf einmal

50 MA 4.1. S. 715 .

$5^{1} \quad$ Goethe an Schiller, 19.4.1797, BW. S. 375 .

$5^{2} \quad$ MA 4.1. S. 859. 
neue Zugriffsmöglichkeiten auf die Stoffe und Formen der Antike. ${ }^{53}$ „Wolf hat den Homer zerstört", wird Goethe genau diesen Sachverhalt in einem späten Tagebucheintrag ausformulieren, „doch dem Gedicht hat er nichts anhaben können; denn dieses Gedicht hat die Wunderkraft wie die Helden Walhallas, die sich morgens in Stücke hauen und mittags wieder mit heilen Gliedern zu Tisch setzten“. ${ }^{54}$ Wolfs Auflösung der epischen Totalität aus historischer und philologischer Perspektive führt tatsächlich zur Neuentdeckung der epischen Form als teilbar und insofern zur Freisetzung des epischen Erzählens überhaupt:

Vielleicht sende ich Ihnen bald mit mehrerem [sic] Mute die Ankündigung eines epischen Gedichtes [Hermann und Dorothea, M.E.], in der ich nicht verschweige, wieviel ich jener Überzeugung schuldig bin, die Sie mir so fest eingeprägt haben. Schon lange war ich geneigt mich in diesem Fache zu versuchen und immer schreckte mich der hohe Begriff von Einheit und Unteilbarkeit der Homerischen Schriften ab, nunmehr da Sie diese herrlichen Werke einer Familie zueignen, so ist die Kühnheit geringer sich in größere Gesellschaft zu wagen und den Weg zu verfolgen den uns Voß in seiner Luise so schön gezeigt hat. [Hervorhebungen M.E. ${ }^{55}$

Gerade aus der rücksichtslosen Infragestellung der epischen Einheit erwachsen nun vielfältige Möglichkeiten, die antike Poetik mit den kunstästhetischen Diskursen der Gegenwart und vor allem den kulturkritischen Zeitdiagnosen zu verbinden. ${ }^{56}$ Nicht zuletzt liegt die Virulenz, die der Eposdebatte der späten 179oer Jahre zu eigen ist, darin begründet, dass sich den Zeitgenossen auf einmal die Chance bietet, selbst „Homeride zu sein“ und sich also auch als Moderner noch einmal an einer hohen Kunst zu beteiligen, anstatt sie nur nachzuahmen. Darin ist ferner sogar eine potenzielle Überwindung des ewigen Antagonismus von Alten und Neuen, den Querelle des Anciens et des Modernes angelegt, den Goethe in Antik und Modern von 1818 affirmativ benennen wird: "Jeder sei auf seine Art ein Grieche! Aber er sei's!“57 Dieser gewandelte, auf die Gegenwart gerichtete Antikenbezug ist denn auch besonders für Friedrich Schlegels frühromantische Programme des modernen Romans ${ }^{58}$ sowie der neuen Mytho-

53 Vgl. hierzu vor allem Wohlleben, Joachim: Goethe and the Homeric Question. In: The Germanic Review: Literature, Culture, Theory 4 (1967). S. 251-275.

54 Goethe zu Eckermann, 1.2.1827, FA II, 12. S. 234.

55 Goethe an Wolf, 26.12.1796, MA 4.1. S. 1085.

$5^{6}$ Vgl. Buschmeier: Epos, Philologie, Roman. Wolf, Friedrich Schlegel und ihre Bedeutung für Goethes Wanderjahre. S. $78 \mathrm{f}$.

57 MA 11.2. S. 5 O1.

$5^{8}$ Vgl. Buschmeier: Epos, Philologie, Roman. Wolf, Friedrich Schlegel und ihre Bedeutung für Goethes Wanderjahre. S. 68-76. 
logie wegbereitend, in welchen "der Rückbezug auf das Urbild mythischer Dichtung“ zur "Lust der Selbstversicherung“ des modernen Poetologen ${ }^{59}$ und insofern die Antike in den Dienst der Autonomie genommen wird.

\subsection{Die deutsche Versepik des 18. Jahrhunderts}

\subsubsection{Klopstocks Messias und Goethes Der ewige Jude}

In den romanistischen Antikendialogen der europäischen Klassizisten war dem Epos, namentlich dem heroischen Versepos, eine prioritäre Rolle zugekommen, was bereits in Barock und Renaissance zu einer eigenständigen, national geprägten Produktion von hochstehenden Epen geführt hatte. In Deutschland bleibt diese Auseinandersetzung aber - zumindest in dieser fruchtbaren Form - zunächst aus, was in der ersten Hälfte des 18. Jahrhunderts dann als Zurückbleiben im internationalen Vergleich und schließlich als Ansporn zu einer eigenen epischen Produktion begriffen wird. ${ }^{60}$ So ausschlaggebend Winckelmanns Griechenideal und das darin so zentral gestellte Epos des Homers für die spätere Hochphase der Eposdebatte in den 179oer Jahre sein werden, in der spätaufklärerischen deutschen Epik kommt dem homerischen Epos eher marginale Bedeutung zu.

Das große, wirkungsmächtige Epos der 179oer Jahre ist Klopstocks Messias - zwischen 1748 und 1773 immer wieder in Teilen publiziert -, der an die europäische Tradition volkssprachlicher und neulateinischer Bibelepik anschließ $\mathrm{t}^{61}$ und in erhabenen Hexametern von Christi Himmelfahrt erzählt. Gut bekannt sind die Szenen aus Dichtung und Wahrheit, die nicht nur die immense Wirkung des Messias auf Goethe illustrieren, ${ }^{62}$ sondern auch auf den allgemein hohen Stellenwert hindeuten, der dem Dichter und seinem Werk zu diesem Zeitpunkt zukommt. Sein Heldengedicht hatte Klopstock

59 Matuschek, Stefan: „Doch Homeride zu sein, auch nur als letzer, ist schön“. Zur Bedeutung der Mythologie bei Friedrich Schlegel. In: Deutsche Vierteljahrsschrift für Literaturwissenschaft und Geistesgeschichte 72, Heft 1 (1998). S. 115-125, hier S. 118.

6o Vgl. Martin, Dieter (Hrsg.): Das deutsche Versepos im 18. Jahrhundert. Studien und kommentierte Gattungsbibliographie. (= Quellen und Forschungen zur Sprach- und Kulturgeschichte der germanischen Völker, Neue Folge 103 = 227). Berlin: de Gruyter 1993 . S. 1. Bodmers und Gottscheds etwa gleichzeitiges Auftreten um 1725 ist dafür ausschlaggebend, beide haben ein stark normatives, systematisches Gattungsdenken und sind von der Vormachtstellung des Epos als höchster Gattung überzeugt. Die Diagnose der verspäteten Nation sowie die Forderung eines repräsentativen deutschen Epos kann auf sie zurückgeführt werden, vgl. ebd. S. 6-10.

$61 \quad$ Vgl. ebd. S. 93.

62 Vgl. HA 9. S. 78-82. 
bereits in seiner Abituriendenrede von $1745^{63}$ als Versuch angekündigt, sich in die oben beschriebene Leerstelle im deutschen Ependiskurs einzuschreiben. Sich gleichwohl in die Bildungstradition der Renaissance einordnend als auch dem Zeitgeist entsprechend ${ }^{64}$ misst Klopstock dem Epos in seiner Abschlussrede unter den Gattungen ${ }^{65}$ den höchsten Rang zu und lobt dabei die antiken Dichter Homer und Vergil als die großen Vorbilder in diesem Fach. ${ }^{66}$ Auf den ersten Blick scheint der Messias tatsächlich in vielem an die Epentradition der Antike anzuschließen, handelt es sich doch um eine groß angelegte Erzählung, die versucht, heilsgeschichtliche Geschehnisse auf einen begrenzten Zeitraum zu konzentrieren und dabei die gängigen Stilmittel erhabener Epik wie Anrufe, Gleichnisse, katalogische Aufzählungen, episodisches Erzählen sowie natürlich die Hexameter-Form bedient. Da die bisherige deutsche Heldenepik fast ausnahmslos in paarweise gereimten Alexandrinern verfasst worden war und insofern in deutlicher Abhängigkeit zur französischen Dichtung stand, kommt Klopstocks Entscheidung für das Versmaß des Hexameters die höchste Bedeutung zu. Mit dem Zurückgreifen auf das antike Versmaß relativiert er nicht nur die Vorbildlichkeit der vor allem französisch dominierten, neuzeitlichvolkssprachlichen Epentradition, sondern trägt darüber hinaus wesentlich zur Begründung einer eigenen deutschen, auf die Griechen gerichteten Antikenaneignung bei, wie sie bei Winckelmann vorgezeichnet wurde.

Obwohl Klopstocks eigentliche Einführung des Hexameters in die deutsche Sprache als ausschlaggebend für die spätere Auseinandersetzung um die angemessene Form des Epischen bezeichnet werden kann, gilt ihm selbst die richtige Stoffwahl als vorrangig gegenüber der äußeren Formgestaltung. An den antiken Gattungsvorbildern bemängelt er deshalb auch vor allem die Bearbeitung mythologischer, anstatt christlicher Gegenstände. Die heidnische Mythologie, die für Winckelmann untrennbar mit dem Epos verbunden war, ersetzt Klopstock deshalb konsequent mit der christlichen Lehre und versucht damit, explizit an John Miltons Paradise Lost anknüpfend, ${ }^{67}$ die antiken

63 „Declamatio, qua poetas epopoeiae auctores recenset F. G. Klopstockius“, zitiert nach dem Erstdruck in: Cramer, Carl Friedrich (Hrsg.): Klopstock: er und über ihn, 1. Teil. Hamburg: gedr. bey G.F. Schniebes 1780. S. 99-132, hier 124-125; Cramers Übersetzung steht dem lateinischen Text voran (ebd. S. 54-98, hier S. 87-88).

64 Vgl. Martin: Das deutsche Versepos im 18. Jahrhundert. Studien und kommentierte Gattungsbibliographie. S. 85 .

65 Vgl. Cramer: Klopstock: er und über ihn, 1. Teil. S. 105; Übersetzung ebd. S. 61.

66 Vgl. Michler: Kulturen der Gattung. Poetik im Kontext 1750-1950. S. 82; Martin: Das deutsche Versepos im 18. Jahrhundert. Studien und kommentierte Gattungsbibliographie, darin das Kapitel Klopstocks Messias. S. 85-139, insb. S. 86 ff.

67 Vgl. Martin: Das deutsche Versepos im 18. Jahrhundert. Studien und kommentierte Gattungsbibliographie. S. 93 f. 
Heldengedichte im Bewusstsein religiöser Überlegenheit zu überbieten. Bereits im ersten Gesang kommt diese Überzeugung vom religiös begründeten Vorrang des eigenen, christlichen Stoffes - namentlich der Passionsgeschichte gegenüber den antiken Mustern deutlich zum Ausdruck:

O so hör ihn, Eloa, wenn er, wie die himmlische Jugend,

Kühn und erhaben, nicht modernde Trümmern der Vorwelt besinget,

Sondern den Bürgern der göttlichen Erde dein Heiligthum aufthut. (I, V. $583-585)^{68}$

An den Invokationen, die den Erzähler in die Nähe der Propheten rücken, ${ }^{69} \mathrm{am}$ traditionellen Anruf am Werkanfang, der sich aber nicht an die Musen, sondern an die „unsterbliche Seele“ (I, V.1) richtet ${ }^{70}$, sowie an der grundsätzlichen Ausrichtung nach innen, die im passiven Leiden des Messias ${ }^{71}$ besonders deutlich wird und den nach außenhandelnden Helden des Altertums entgegensteht, ${ }^{72}$ lässt sich Klopstocks Agon gegen die Antike ablesen. Für den jungen Goethe ist die mal spielerische, mal ernste Auseinandersetzung mit dem 25 Jahre älteren Klopstock von höchster Bedeutung ${ }^{73}$ und 1774 ist es der Messias, der ihn zu seinem ersten ${ }^{74}$ eigenen Epen-Projekt veranlasst. Mit dem Fragment Der ewige Jude wendet er sich aber gerade so deutlich gegen das große Vorbild, wie er daran anschließt. ${ }^{75}$ Wohl orientiert Goethe sein Epos thematisch ebenfalls an

68 Fassung von 1748, zitiert nach Martin, Dieter: Klopstocks Messias und die Verinnerlichung der deutschen Epik im 18. Jahrhundert. In: Kohl, Katrin; Hilliard, Kevin F. (Hrsg.): Klopstock an der Grenze der Epochen. Berlin: de Gruyter 1995. S. 97-116, hier S. 101 f.

69 Vgl. ebd.

70 Martin: Das deutsche Versepos im 18. Jahrhundert. Studien und kommentierte Gattungsbibliographie. S. 138 .

71 Zum besonderen Verhältnis von Handlung und Teilhabe in Klopstocks Messias vgl. Martin: Klopstocks Messias und die Verinnerlichung der deutschen Epik im 18. Jahrhundert. S. 97-116.

72 Vgl. ebd. S. 107.

73 Vgl. Lee, Meredith: Eingeleiert in Klopstocks Rhythmik: Der Messias und Goethes Fragment Der ewige Jude. In: Kohl; Hilliard (Hrsg.): Klopstock an der Grenze der Epochen. S. 117-131, hier S. 118.

74 Genau genommen war Goethes erster Versuch im epischen Fach die Geschichte Josephs, die allerdings in Leipzig den Flammen zum Opfer fiel, vgl. Mommsen, Katharina: Goethes Morgenlandfahrten. In: Goethe Jahrbuch 116 (1999). S. 281-29o. S. 282.

75 Goethe selbst gibt keinen eindeutigen Hinweis darauf, dass sein Der ewige Jude gegen Klopstocks Messias gerichtet sei, er schreibt aber im August 1774 an Johanna Faimer von einem neuen Werk, das vielleicht „ein neuer Messias“ werde: „Dancke besonders für die gütige Theilnehmung an der Schätzung des Volcks die ich vornehme, vielleicht wird während der Zeit ein neuer Messias im Stall gebohren“, zitiert nach Fischer-Lamberg, Hanna (Hrsg.): Der junge Goethe (neu bearbeitete Ausgabe in fünf Bänden, Bd. IV). Berlin: de Gruyter 1963-74. S. 247. Die Forschung sieht ihrerseits den engen Zusammenhang 
der Kreuzigungsgeschichte und lässt sich dafür von den Volksbüchern des 17 . Jahrhunderts inspirieren:

Weil nun aber alles, was ich mit Liebe in mich aufnahm, sich sogleich zu einer dichterischen Form anlegte, so ergriff ich den wunderlichen Einfall, die Geschichte des ewigen Juden, die sich schon früh durch die Volksbücher bei mir eingedrückt, episch zu behandeln, um an diesem Leitfaden die hervorstehenden Puncte [sic] der Religions- und Kirchengeschichte nach Befinden darzustellen. ${ }^{76}$

Gemäß dieser durchaus selbstinszenatorisch motivierten Aussage in Dichtung und Wahrheit hätte Der ewige Jude eine diachrone Religionsgeschichte werden sollen, ${ }^{77}$ das vermag das in zwei größere und mehrere kürzere Bruchstücke zerfallende Fragment allerdings nicht zu leisten. Goethe sucht damit nicht nur die Auseinandersetzung mit der Religions- und Kirchengeschichte sowie mit den protestantischen Zuständen seiner Zeit, sondern vor allem auch mit den eigenen religiösen Überzeugungen. In seinen Jugendjahren hatte er sich intensiv mit religiösen und kirchenkritischen Fragen beschäftigt und dabei die Vorstellung eines toleranten, spirituellen und unkirchlichen Urchristentums verfolgt. ${ }^{78}$ Die kurz vor dem Ewiger-Jude-Fragment entstandenen Schriften ${ }^{79}$ vermitteln aber auch Goethes Einsicht in die historische Bedingtheit der verschiedenen Phasen des Christentums, seiner Konflikte und konfessionellen Abspaltungen. Für Meredith Lee ist deshalb klar, dass sich Goethe zu diesem Zeitpunkt von religiösen Ideen und Bindungen zu distanzieren beginnt, weder länger an ihnen teilnehmen kann noch will und ihm diese Entfernung auch klar ins Bewusstsein tritt. ${ }^{80}$

zwischen Messias und Der ewige Jude als erwiesen an, vgl. ebd. S. 347-348; Minor, Jacob: Goethes Fragmente vom ewigen Juden und vom wiederkehrenden Heiland. Ein Beitrag zur Geschichte der religiösen Fragen in der Zeit Goethes. Stuttgart: Cotta 1904. S. 89 und 101-102; Staiger, Emil: Goethe, Bd. 1. Zürich: Atlantis Verlag $195^{2}$ ff. S. 125-129; Lee: Eingeleiert in Klopstocks Rhythmik: Der Messias und Goethes Fragment Der ewige Jude. S. 117-131; Berning, Matthias: „Der neue Messias im Stall“. Goethes Fragment Der ewige Jude und die Verselbständigung des Epitextes. In: Berning, Matthias; Jordans, Stephanie et al. (Hrsg.): Fragment und Gesamtwerk. Relationsbestimmungen in Edition und Interpretation. Kassel: kassel university press $\mathrm{GmbH}$ 2015. S. 117-128.

76 HA 10. S. 45 .

77 Vgl. Berning: „Der neue Messias im Stall“. Goethes Fragment Der ewige Jude und die Verselbständigung des Epitextes. S. 117-128, hier S. 119.

78 Vgl. ebd. S. 120.

79 Brief des Pastors zu xxx an den neuen Pastor zu xxx, Zwo wichtige bisher unerörterte biblische Fragen. WA I, 37. S. 153-19o.

8o Vgl. Lee: Eingeleiert in Klopstocks Rhythmik: Der Messias und Goethes Fragment Der ewige Jude. S. 117-131, hier S. 125 . 
Vor diesem Hintergrund wird einsehbar, dass Goethe kein ernstgemeintes religiöses Versepos in der Nachfolge des Messias schreiben konnte, sondern vielmehr eine kritische Position dazu beziehen wollte. In Goethes Der ewige Jude steht die Passion Christi denn auch nicht am Schluss als Vollendung des göttlichen Schöpfungsplans, sondern gerade am Anfang der Erzählung, die damit mehr zu einer Weltgeschichte mit offenem Ausgang wird, anstatt die Heilsgeschichte mit ihrem festgelegten Ausgang wiederzugeben. Zentraler Protagonist ist nicht der große Heilsbringer, sondern ein heimatloser Jude, der stark an die aus den Volksbüchern bekannte Ahasver-Figur angelehnt ist. ${ }^{81}$ Dieser in Jerusalem beheimatete und mit dem Verrat des Judas in Verbindung stehende Schuster begegnet Jesus auf dessen Kreuzweg, wobei er dem Leidenden keinerlei Mitleid entgegenbringt und dafür als Strafe bis zur Wiederkehr Christi rastlos auf Erden herumwandern muss.

Während Klopstock im Messias also den Triumph Christi als eine ausgedehnte Himmelsfahrt feiert, kehrt Christus in Goethes Fragment schließlich auf die Erde zurück, wo er eine trostlose Welt antrifft, aus der alle Zeichen seiner Gegenwart verschwunden sind - anstatt Erlösung zu zelebrieren, weist Goethe gerade auf deren Vergeblichkeit hin. ${ }^{82}$ So deutlich die inhaltlichen Parallelen zwischen den beiden Werken sind, so konsequent verkehrt Goethe die klopstockschen Motive in ihr Gegenteil und setzt sich damit sowohl von dem pietistischen Programm als auch dem pathetischen Ton der Vorlage parodistisch ab. Durch die distanzierende Wirkung des Komischen versucht Goethe der Verunsicherung, die er in Bezug auf religiöse wie auch poetologische Fragen erlebt, entgegenzuwirken und sich gleichzeitig eine eigene Stimme, eine eigene poetische Identität zu verschaffen. ${ }^{83}$

In diesem Zusammenhang ist auch Goethes Vorhaben, den Ewigen Juden in Knittelversen zu verfassen, sowohl als Emanzipationsgestus gegenüber Klopstock als auch als früher, impliziter Erneuerungsversuch der epischen Form zu verstehen. So sehr Goethe den älteren Klopstock als Schöpfer einer neuen Dichtersprache geschätzt hatte, wie im Lektürekapitel zu Hermann und Dorothea noch zu sehen sein wird, vermochte er sich doch weder an dessen religiös bestimmte Auffassung vom Poeten als göttlichem Boten auf Erden noch an das fromme Pathos des Messias anzuschließen. Mit dem holprigen, ungeschliffenen und teilweise derben Versmaß der mittelalterlichen Schwänke

81 Vgl. Anderson, George Kumler: The Legend of the Wandering Jew. Hanover: Brown University Press 1991, hier S. 45-48.

82 Vgl. Lee: Eingeleiert in Klopstocks Rhythmik: Der Messias und Goethes Fragment Der ewige Jude. S. 117-131, hier S. $126 \mathrm{f}$.

83 Vgl. ebd. S. 121. 
lässt sich eine größtmögliche Entgegensetzung zum Messias und seiner kunstvoll-eleganten Hexameter-Metrik gestalten, ${ }^{84}$ darüber hinaus wird aber auch ein spannungsvolles Verhältnis zwischen dem traditionellen Verständnis des Epos als hoher Gattung und der formalen Ausführung im niederen Stil erzeugt. Insofern eröffnen sich Goethe über das Projekt des Ewigen Juden schon früh alternative Möglichkeiten des epischen Erzählens. Anstatt heiliger, aber weltfremder Poesie hätte er ein Epos über die Welt als gottverlassener, dem Versmaß des Hexameters unwürdiger und deshalb nur in Knittelversen adäquat zu beschreibender Ort geschrieben. Der ewige Jude sollte die Motive und Formsprache des Messias in eine andere, neue Poetologie des Epischen überführen, eine solche, die den Erscheinungen und Problemen der gegenwärtigen Erfahrungswelt gerecht würde.

\subsubsection{Wielands Oberon und Goethes Geheimnisse}

Darauf, dass es sich beim Ewigen Juden nicht bloß um eine zufällige Alternative zum Bibelepos, sondern um eine bewusste Gattungsreflexion handelt, deutet auch Goethes Auseinandersetzung mit dem anderen wirkungsmächtigen Epos des späten 18. Jahrhunderts, Wielands Oberon - ein romantisches Heldengedicht, hin. ${ }^{85}$ Bei dem zwischen 178 o und 1784 veröffentlichten Werk handelt es sich um einen Versuch, das italienische Renaissance-Epos im Stil von Ludovico Ariostos Orlando Furioso zu restaurieren, ${ }^{86}$ das mit seinen leisen, aber geistreichen Zweideutigkeiten an die komisch-erotische Epentradition des Mittelalters anschließt. ${ }^{87}$ Für seine von Shakespeares Sommernachtstraum inspirierte Liebesgeschichte im Feenreich bedient Wieland sowohl den ironisch-unterhaltsamen Ton als auch die flexiblen Stanzen der Vorlage und schlägt damit einen ganz anderen Weg ein als Klopstock. Die Handlung teilt sich in zwei kunstvoll ineinandergeflochtene Erzählstränge, die von zwei Paaren - Hyon und Rezia, und Oberon und Titania - erzählen, deren Liebe durch zahlreiche vergnügliche Intrigen geprüft wird. Die Märchendichtung knüpft an die Ritterromane hohen Stils ebenso an wie an deren spätere

84 Inwiefern der Kontrast zwischen Knittelvers und Hexameter von den Zeitgenossen an Hans Sachs zum einen und Klopstock zum anderen festgemacht wurde, allgemein gut bekannt war und benutzt wurde, vgl. ebd. S. 123-125.

85 Vgl. Michler: Kulturen der Gattung. Poetik im Kontext 1750-195o. S. 264.

86 In der Vorrede nennt Wieland „Romanzen und Ritterbücher“ des Mittelalters, „die fabelhafte[n] Götter- und Heldengeschichte[n] der Morgenländer und der Griechen“ sowie „Bojardo, Ariost, Tasso, Allemanni, und andere“ als seine Inspirationsquellen, vgl. Christoph Martin Wieland: Oberon. In: Werke. Band 5, München 1964 ff. S. 162.

87 Vgl. Dietrich, Wolfgang: Die Geheimnisse, Achilleis, Das Tagebuch. In: Lützeler, Paul Michael; McLeod, James E. (Hrsg.): Goethes Erzählwerk. Interpretationen. Stuttgart: Reclam 1985. S. 268-29o, hier S. 268 f. 
Parodien und verbindet insofern ironische Distanz mit Abenteuerlust und Erzählfreude. Dem Wunderbaren wird dabei in Form von Zaubertränken, magischen Bechern und eisernen Kämpen besonders viel Raum gegeben. Wie die italienischen Stanzendichtungen zeichnet sich auch Wielands wunderbarromantisches Märchen-Epos durch eine enorme Dichte an plastischen sowie figürlichen Schilderungen aus, die den hohen Unterhaltungswert der Dichtung ausmachen und den Oberon besonders im 19. Jahrhundert nicht nur zu Wielands bekanntestem Werk avancieren lassen, sondern überhaupt zu einem oft rezipierten Muster der Nachfolgegeneration. Auch formal orientiert Wieland sein Versepos an der klassischen Stanzenform, folgt dabei allerdings weder einem regelmässigen Metrum noch einem konsistenten Reimschema. ${ }^{88}$ Er setzt sich damit von Klopstocks Messias wie von Homer und der antiken Gattungstradition ab, was ihm nicht nur Anerkennung einbringt.

Auch Goethe hatte spätestens seit 1773 ein ambivalentes Verhältnis zu Wieland: In seiner Funktion als Prinzenerzieher hatte Wieland in diesem Jahr das Singspiel Alceste geschrieben und damit bewusst versucht, die antike Vorlage zu überbieten. ${ }^{89}$ Mit diesem anmaßenden Umgang mit den Alten zeigte sich der junge Goethe gar nicht einverstanden und zitierte Wieland in seiner Satire Götter, Helden und Wieland in den Tartaros, wo er ihn mit antiken Dichtern und Helden, vor allem aber Euripides konfrontierte, gegen dessen Tragödie Wieland opponiert hatte. Unter dem Eindruck der eigenen Auseinandersetzung mit der Renaissanceliteratur fasst Goethe 1784 dann seinerseits den Plan, ein weitläufig angelegtes, episches Gedicht in Stanzen zu verfassen, das den Titel Die Geheimnisse tragen sollte. ${ }^{90}$ Die Verserzählung hätte in gesetztem Ton von der Gebirgswanderung des jungen Bruder Markus gehandelt, der auf Irrwegen zu einem Kloster gelangt, dessen zwölf Rittermönche nach dem Tod ihres Ordensleiters den jungen Mönch zu ihrem neuen Oberhaupt wählen. ${ }^{91}$ In der geschilderten Bruderschaft entwirft Goethe ein unorthodoxes Christentum bzw. die Vorstellung einer humanistisches Urreligion, die alle Religionen umfasst und in der alle nach Religiosität strebenden Menschen zusammenfinden. ${ }^{92}$

Die Kritik an Wieland bildet nun gerade den entscheidenden Hintergrund für Die Geheimnisse, die die poetologischen Eposdebatten der Renaissance,

88 Vgl. Wieland, Christoph Martin: Werke, bearbeitet von Hans-Peter Nowitzki und HeinzGünther Nesselrath, Bd. 15.1. Berlin: de Gruyter 2012.

89 Vgl. Michler: Kulturen der Gattung. Poetik im Kontext 1750-195o. S. 263.

90 Vgl. HA 2. S. 705 .

91 Goethe selbst liefert 1816 in Cottas Morgenblatt eine Interpretation nach, die über den Inhalt des Werks Auskunft gibt und den Plan versucht einzuordnen vgl. HA 2. S. $281 \mathrm{ff}$.

92 Vgl. HA 2. S. 705. 
an denen sich Torquato Tasso mit seinen Discorsi dell' arte poetica sowie den Discorsi del poema eroico besonders prominent beteiligt hatte, zu einer anderen Restitution des ernsten Religionsepos nutzen als es Klopstock getan hatte. Goethe schickt die Zueignung des Gedichts mit der Bemerkung an Herder, „was ich hier schicke ist zum Eingang bestimmt, statt der hergebrachten Anrufung ${ }^{493}$. Damit bezieht er sich auf die invocatio, den Musenanruf, der mit der propositio zu den traditionellen Eingangsstellen des Epos gehört und insofern auf den von Tasso mitgeprägten renaissancistischen Gattungsdiskurs, der in Erneuerung der aristotelischen Poetik und dem Wiederbeleben traditioneller Gattungen solche festen Formelemente als unumstößliche Bestandteile der Epentradition festgelegt hatte. ${ }^{94}$

Auf ein an die Renaissancetradition anschließendes Gattungsverständnis verweisen neben dem Gebrauch der Formensprache auch einige auf Tasso bzw. Petrarca zurückgreifende Motive, ${ }^{95}$ der gravitätische Ton und vor allem die strenge Stanzenform. Goethe hatte unter den deutschen Versmaßen alleine dem Knittelvers komisches Potenzial zugestanden, was ihm das Schreiben eines komischen Epos in Stanzen ohnehin verunmöglichte. ${ }^{96}$ Mit der Abweichung von der komisch-erotischen Stanzentradition der italienischen Poesie leistet Goethe die eigentliche Begründung einer eigenen, deutschen Stanze. Damit stehen sich nun Die Geheimnisse und Wielands Oberon inhaltlich, stilistisch sowie formal diametral gegenüber, und zwar im Sinne einer bewussten, gattungsinternen Antithese: Goethe setzt Tasso gegen Ariosto, regelhafte gegen freie Stanzen, das Wunderbare der Religion gegen dasjenige des Märchens, Ernsthaftigkeit gegen Komik. Anstelle unterhaltsamer Kabalen liefert Goethe einen esoterischen Gründungsmythos, anstelle romantischer Liebensgeschichte ein welthaltiges Lehrgedicht. Das Geheimnisse-Projekt steht also in engem Zusammenhang mit Goethes Beschäftigung mit Torquato Tasso sowie dessen gerusalemme liberata, die im ersten Weimarer Jahrzehnt das Gravitätszentrum seines poetischen Denkens bildet, und bedeutet gleichzeitig auch in vielerlei Hinsicht eine polemische Wendung gegen Wielands Oberon, wie Werner Michler einleuchtend aufgezeigt hat. ${ }^{97}$

93 Goethe an Herder, 8.8.1784, WA IV, 6. S. 333.

94 Vgl. Michler: Kulturen der Gattung. Poetik im Kontext 1750-195o. S. $25^{8}$.

95 Vgl. ebd. S. 259.

96 Vgl. Dietrich: Die Geheimnisse, Achilleis, Das Tagebuch. S. 268-29o, hier S. 270.

97 Vgl. Michler: Kulturen der Gattung. Poetik im Kontext 1750-195o. S. 263 f. 


\subsection{Die Französische Revolution im deutschen Klassizismus}

\subsubsection{Die Restitution des Epischen als konservativer Reflex? Revision einer Forschungsmeinung}

Für die hier in den Fokus genommene Zeit um 18oo liegt der bereits angedeutete Zusammenhang zwischen systemumfassender Krisenerfahrung und einem sich daraus speisenden Bedürfnis nach einem reintegrativen, epischen Erzählen auf der Hand: Der von Klassizisten wie Romantikern gleichermaßen forcierte Gattungsdiskurs fällt in das zeitliche Umfeld der Französischen Revolution und der mit ihr einhergehenden Legitimationsverlusten der traditionellen Gesellschaftsordnung sowie der etablierten Wissenssysteme. ${ }^{98}$ Neben den prekär gewordenen Kultur- und Geschichtsbegriffen sind es besonders die nun in Ermangelung verbindlicher Identitätsentwürfe neu auftauchenden Begriffe von Volk, Nation und Bürgertum, die vorerst Konstruktionen ohne tradierten sozialen Gehalt sind und zuerst noch mit verbindlicher Bedeutung angefüllt bzw. als Kategorien konstituiert werden müssen.

Über die große Wirkung, die das historische Ereignis der Revolution weit über Frankreich hinaus und gerade auch auf die deutschen Zeitgenossen hatte, besteht in der kulturwissenschaftlichen Forschung kein Zweifel. ${ }^{99}$ Besonders Goethe wird gemeinhin als entschiedener Gegner der Revolution angesehen, als Verfechter der konstitutionellen Monarchie, in deren Verwaltungsapparat er schließlich selbst eingebunden war. Das hat ihm den Ruf eines Reaktionärs eingebracht, der sich dezidiert gegen alles Neue und Moderne stellt und sich nach Kräften bemüht, den status quo zu konservieren - ja, sogar die Verhältnisse der Vergangenheit zu restaurieren. Hans Blumenberg bestätigt dieses Goethebild noch 1999, wenn er dem Dichter eine zunehmende Versteifung und Entfremdung als Reaktion auf die historischen und persönlichen Veränderungen der Revolutionszeit attestiert. ${ }^{100}$ Und nach wie vor tendiert die Forschung dazu, Goethes forcierte Antikenaneignung zwischen 1797 und 1805 als klassizistische Bemühung aufzufassen, einen bewährten, antiken Kunstbegriff als normativen Maßstab in die Gegenwart hinein zu tragen und

98 Vgl. Valk: Heikle Balancen. Die Weimarer Klassik im Prozess der Moderne. S. 9.

99 Vgl. Jaeger, Michael: Fausts Kolonie. Goethes kritische Phänomenologie der Moderne. Würzburg: Königshausen \& Neumann 2005 und Willems, Gottfried: „Ich finde auch hier leider gleich das, was ich fliehe und suche, nebeneinander“. Das Italienbild in Goethes Römischen Elegien und Venetianischen Epigrammen und die Klassik-Doktrin. In: Manger, Klaus (Hrsg.): Italienbeziehungen des klassischen Weimar (= Reihe der Villa Vigoni, Bd. 11). Tübingen: Niemeyer 1997. S. 127-149.

100 Vgl. Blumenberg, Hans: Goethe zum Beispiel, in Verbindung mit Manfred Sommer hrsg. v. Hans-Blumenberg-Archiv. Frankfurt a. M., Leipzig: Suhrkamp 1999, dort insb. S. 63 f. 
darin eine eindeutige Markierung der Werkteilung zu sehen. Diese an Hegel anschließende Tradition handelt neben dem Propyläen-Projekt auch explizit die Hinwendung zum Epischen als Ausdruck einer als ausgemacht geltenden, konservativen Grundhaltung Goethes und den Rekurs auf die antiken Formen als Gegenwartsflucht ab, deren gemeinsamer Auslöser die Revolutionserfahrung sei.

Weniger einig ist man sich allerdings über die tatsächliche Einsicht Goethes und seiner Zeitgenossen in die tiefere, strukturelle Bedeutung der Revolution: Dass sie ein Ereignis welthistorischen Ausmaßes sei, das hätten die großen Dichter und Denker sehr wohl erkannt, worin ihre Bedeutung jedoch bestand, das hätten sie nicht verstanden, gar nicht verstehen können. ${ }^{101}$ Diese Argumentation legt die Revolutionserfahrung als Schlüsselerlebnis einer ganzen Dichter-Generation aus, das die schematische Abkehr von der regelbefreiten, geniezentrierten Sturm-und-Drang-Poetik und Rückwendung auf die normative, strengdifferenzierende Formenästhetik des Klassizismus auslöst. Gleichzeit versteht sie die Zeitzeugen der Revolution als in den Ereignissen und ihrer Abfolge befangen. Ihre literarischen Auseinandersetzungen mit den Geschehnissen werden nicht als Reaktionen auf die Revolution als zusammenhängendes Ganzes gedeutet, sondern als Bewältigungsversuche von Singularitäten. ${ }^{102}$ Ein tieferes Verständnis dafür, dass die aus der Revolution gespeisten Veränderungen einen umfassenden Modernisierungsschub bedeuten, einen Umsturz nicht nur der unmittelbaren politischen Verhältnisse, sondern sämtlicher politischen und sozialen Kategorien sowie des bisherigen ästhetischen Referenzsystems - das Ende der Tradition nach Hegel - wird Goethe und seinen Zeitgenossen damit aber allzu pauschal abgesprochen. Wie die jüngsten, traditionsskeptischen Forschungsbemühungen nämlich einleuchtend nachweisen, haben die Akteure der Epochenschwelle die Tragweite und Drastik des umfassenden Paradigmenwandels der Moderne und

101 Die Münchner Gesamtausgabe unternimmt eine präzise historische Einordnung der Goethe-Texte, in denen er sich mit der Revolution beschäftigt. Sie zeigt auf, dass diese nicht Reaktionen auf die Revolution darstellen, sondern unterschiedliche Reaktionen auf verschiedene Phasen der Revolution. Der Ausgabe gelingt es dadurch, Goethes Schaffen einerseits als stärker politisch motiviert aufzuzeigen, als das die bisherige Forschung getan hat, und andererseits auch als flexibler und experimentierfreudiger. Obwohl diese feinteilige Werkanalyse erhellende Einblicke in die wechselhafte Haltung Goethes gegenüber der Revolution gewährt, bleibt sie dem Standpunkt verhaftet, dass ihm als Zeitgenosse die nötige Distanz fehle, um deren tieferliegende Bedeutung zu erkennen und dass sich die Revolution Goethe nicht wie dem nachfolgenden Historiker als das eine große Ereignis präsentiere, sondern als einzelne Vorfälle, deren rasante Abfolge die literarische Bewältigungsarbeit überfordert, vgl. MA 4.1. S. 921.

102 Vgl. MA 4.1. S. 919. 
die katalysierende Funktion der Revolution dafür sehr wohl verstanden, mehr noch verhandeln sie dieses Wissen in ihren literarischen und theoretischen Auseinandersetzungen und stellen es vielfältig aus. ${ }^{103}$ Daran will die hier angestrebte Neuperspektivierung der gattungstheoretischen Eposdebatte anschließen. Die verkürzte Perspektive auf die antikenbegeisterte deutsche Philologie der Revolutionszeit als konservativer Reflex wird nämlich weder ihrem literarischen und theoretischen Gehalt gerecht - bietet die Diskussion um das Epische doch, wie bereits angedeutet, gerade Gelegenheit, sich mit modernen Problematiken auseinanderzusetzen - noch der tatsächlichen ästhetischen Anarchie der Zeit, dem hierarchielosen Nebeneinanderexistieren verschiedener Kunstauffassungen und -strömungen sowie deren komplexen, wechselseitigen Beziehungen. ${ }^{104}$

Goethes Blick nach Paris ist stets ein kritischer, die große Euphorie Friedrich Ludwig Klopstocks, ${ }^{105}$ der sogar in die französische Hauptstadt reist, um das Fest der Freiheit aus nächster Nähe mitzuerleben, ${ }^{106}$ aber auch Friedrich Hölderlins und Christoph Martin Wielands, teilt er nicht. Wie viele seiner Zeitgenossen beurteilt Goethe die Ideale von Freiheit und Gleichheit, denen er selbst zeitlebens anhängt, sowie die ersten Reformen der revolutionären Bewegung von 1789 - das Ende der feudalen Ständegesellschaft, das Einrichten einer konstitutionellen Monarchie und die Erklärung der Menschenrechte - zwar weitgehend positiv. Wenn er im verhältnismäßig friedlichen Zwischenjahr 1790

103 Als wegweisend darf hier wohl Heinz Brüggemanns Studie Modernität im Widerstreit bezeichnet werden, die die kulturelle Moderne als „longue durée“ seit der Aufklärung auffasst und auch der Sattelzeit das Epochenbewusstsein von Krise, problematischer Neubegründung und Pluralität attestiert, vgl. Brüggemann: Modernität im Widerstreit. Zwischen Pluralismus und Homogenität. Eine Theorie-, Kultur- und Literaturgeschichte (18.-20. Jahrhundert). Dem vom Thorsten Valk herausgegeben Sammelband Heikle Balancen. Die Weimarer Klassik im Prozess der Moderne gelingt es zudem, fast allen kulturschaffenden Repräsentaten der Epochenschwelle ein sensibles Modernitätsbewusstsein nachzuweisen, das epistemische, anthropologische und kunsttheoretische Innovationsansätze integriert.

104 Vgl. Christians: Der Traum vom Epos. Romankritik und politische Poetik in Deutschland (1750-2000). S. 127 und Schulz, Karlheinz: Wandlungen und Konstanten in Goethes Ästhetik und literarischer Laufbahn. Goethezeitportal.

http://www.goethezeitportal.de/fileadmin/PDF/db/wiss/goethe/schulz_wandlungen_ konstanten.pdf; Erstpublikation: 11.5.2010 [abgerufen am 20.12.2016].

105 Vgl. Vierhaus, Rudolf: „Sie und nicht Wir“. Deutsche Urteile über den Ausbruch der Französischen Revolution. In: Voss (Hrsg.): Deutschland und die Französische Revolution. 17. Deutsch-Französisches Historikerkolloquium des Deutschen Historischen Instituts Paris (= Beihefte der Francia, 12). München, Zürich: Artemis 1983. S. 1-15.

106 Vgl. Alt, Peter-André (Hrsg.): Schiller: Leben, Werk, Zeit, Bd. 2 von 2. München: Beck 2000. S. 113. Auch Heinrich Campe und Georg Forster reisen in das revolutionäre Paris. 
an Friedrich Heinrich Jacobi schreibt, „dass die Französische Revolution auch für mich eine Revolution war" ${ }^{107}$, dann ist damit Hinweis darauf gegeben, dass Goethe die erneuernde Energie der Revolutionsbewegung nicht nur erfasst, sondern ganz bewusst für sein eigenes Denken und Schaffen produktiv macht. Wie weiter unten noch genauer ausgeführt werden soll, setzt dieser durchaus bedeutende Wandel in Goethes Denken jedoch bereits mit der persönlichen Identitätskrise von $1786^{108}$ ein und lässt sich daher nicht einseitig aus der Revolutionserfahrung erklären. Die Skepsis gegenüber der Französischen Revolution gründet zum einen in Goethes kategorischer Verurteilung jeglicher Gewalt und zum anderen in seiner damaligen Wahrnehmung des Volkes als einer leicht manipulierbaren, gewaltbereiten Manövriermasse. ${ }^{109}$ Die weiter unten vorgestellten Textstellen des Reineke Fuchs werden das gleich deutlich machen.

Die blutigen Ereignisse des Jahres 1792 bringen deshalb nicht nur für die meisten deutschen Intellektuellen, sondern insbesondere auch für Goethe den endgültigen Wendepunkt in der Revolutions-Wahrnehmung. ${ }^{110}$ Sogar für Schiller, der die Revolution bis dahin als das „vollkommenste aller Kunstwerke" beschrieben hat, da sie den „Bau einer wahren politischen Freiheit"111 angestossen habe, und der 1792 noch als Ehrenmitglied in die neue französische Nationalversammlung gewählt worden war, ändert sich mit dem Ausbruch des Terrors, vor allem der Hinrichtung Louis XVI im Januar 1793, alles. Enttäuscht über die Brutalität und Willkür, die die Schrecken des Ancien Régime noch zu übersteigen scheinen, wendet er sich von der Revolution und darüber hinaus auch ein Stück weit von der Politik ab, hin zu den Möglichkeiten einer gewaltfreien, rein ästhetischen Reformbewegung, die die Menschheit durch Schönheit zu Humanität und Vernunft führt. Mit dem ersten Koalitionskrieg und der Besetzung oberrheinischen Gebiets durch französische Truppen greift die innerfranzösische Katastrophe - die zahlreichen Opfer des Tuileriensturms, die massenhaften Ermordungen und Hinrichtungen von Adligen, die Flucht des Königs in die Nationalversammlung und dessen anschließende

107 Zitiert nach MA 4.1. S. 917 (Einführung).

108 Vgl. Goethe, Johann Wolfgang von: MA 4.1. S. 915 f. (Einführung).

109 Vgl. MA 4.1. S. 925. Zu Goethes Volksbegriff und seinen Wandlungen vgl. Mommsen, Wilhelm: Die politischen Anschauungen Goethes. Stuttgart: Deutsche Verlagsgesellschaft 1948. S. 25 ff.; Marianelli, Marianello: Die Idee der Entwicklung im Spiegel von Goethes Italienische Reise. In: Goethe Jahrbuch 99 (1982). S. 117-132 und Bahr, Ehrhard: Volk. In: Witte, Bernd; Janssen, Carina et al. (Hrsg.): Goethe Handbuch in vier Bänden, Band 4.2. Stuttgart: Metzler 2004. S. 1102-1105.

110 Vgl. Vierhaus: „Sie und nicht Wir“. Deutsche Urteile über den Ausbruch der Französischen Revolution. S. 1-15.

111 Oschmann, Dirk: Friedrich Schiller. Wien, Köln, Weimar: Böhlau 20og. S. 86. 
Absetzung - unerwartet heftig auf die europäischen Monarchien über. Durch das Einrichten einer radikaldemokratischen und vor allem militärisch schlagkräftigen Republik in Frankreich sind auch die umliegenden, ständisch organisierten Staaten grundsätzlich und mit erneuter Vehemenz in Frage gestellt. Für Goethe, der als Begleiter des Herzogs Karl August, den Feldzug gegen Frankreich von 1792 sowie die Belagerung von Mainz im Frühjahr darauf selbst miterlebt und davon tief betroffen ist, ${ }^{112}$ wird die Revolution mit „diesem gräßlichen Unheil [gemeint ist die Guillotinierung Ludwigs XVI.] “113 mit einem Schlag zum „schrecklichsten aller Ereignisse. ${ }^{“ 14}$

\subsubsection{Goethes Reineke Fuchs}

Genau in diese Zeit, als sich die Französische Revolution als fatale Welterschütterung erweist, fällt Goethes Bearbeitung des alten Tierepos vom Reineke Fuchs. ${ }^{115}$ Den entscheidenden Hinweis auf diese „Fabel der Welt, aller Berufsarten, Stände, Leidenschaften und Charaktere" und vor allem ihr Potenzial zu einer „deutsche[n] Epopee ${ }^{416}$ verdankt er Herder. Das Werk wird eine schonungslose Abrechnung sowohl mit den höfischen Intrigen des Ancien Régime und der amoralischen Heuchelei der Kirche wie auch mit der radikalen Unnachgiebigkeit der Revolution. „Hier kommt Reineke Fuchs, der Schelm“, schreibt Goethe an Charlotte von Kalb, „[D]a dieses Geschlecht auch in unserer Zeit bei Höfen, besonders in Republiken sehr angesehen und unentbehrlich ist, so möchte nichts billiger sein, als seine Ahnherrn recht kennen zu lernen“..117 Inhaltlich ändert Goethe nur wenig an den alt bekannten Geschichten, die Gottsched zuletzt $175^{2}$ in eine wirkungsmächtige neuhochdeutsche Prosaerzählung ${ }^{118}$ übersetzt hatte, erweist sich das alte satirische Volksbuch doch als hervorragendes Gefäß für die eigene Kritik an den Zuständen der Gegenwart: „Vor Jahrhunderten hätte ein Dichter dieses gesungen? Wie ist das möglich? Der Stoff ist ja von gestern und heut."119 In Goethes prägnantem Kommentar klingt bereits eine frühe, implizite Vorstellung davon an, dass sich Historizität und Überzeitlichkeit nicht unbedingt gegenseitig ausschließen müssen, sondern gerade auf spannungsvolle Weise ineinandergreifen können. Schon

\footnotetext{
112 Vgl. MA 14. S. 517 ff. und S. $756 \mathrm{ff}$.

113 MA 14. S. 517.

114 MA 12. S. 308.

115 Vgl. Jäger, Hans-Wolf: Nachwort. In: Goethe, Johann Wolfgang von: Reineke Fuchs. Stuttgart: Reclam 2002. S. 177-206, hier S. 178.

116 HA 2. S. 718.

117 Goethe an Charlotte von Kalb, 28.6.1794, zitiert nach HA 2. S. 714.

118 Vgl. Jäger: Nachwort. In: Goethe: Reineke Fuchs. S. 181.

119 Aus den Xenien, 1796, zitiert nach HA 2. S. 715.
} 
die mittelalterliche Fuchs-Fabel war ein höchst politischer Welt- und Regentenspiegel, prall gefüllt mit spezifischem Zeitwissen über weltliche und geistliche Machtverhältnisse, Rechtswesen, Moralbräuche und stereotype Rollenbilder. Auch Goethes Reineke präsentiert noch eine mittelalterliche Welteinrichtung, in deren Zentrum ein korrupter Königshof und seine amoralische Vasallengesellschaft stehen, die von einem Außenseiter vorgeführt werden. Die wenigen neuen Verse, die Goethe der tradierten Geschichte hinzufügt, stellen dann aber jeweils einen Bezug zum aktuellen Weltgeschehen her und offenbaren Goethes klare Absicht zur Gegenwartskritik. Die folgende zornige Stelle aus dem 8. Gesang aktualisiert und radikalisiert etwa die Hof- und Kirchenschelte des überlieferten Erzählkorpus entschieden und stellt insofern eine pessimistische Zeitdiagnose dar:

[...] es bleiben die Besten

Doch nicht unberedet in diesen Zeiten vom Volke.

Denn es weiß die Menge genau nach allem zu forschen,

Niemand vergessen sie leicht, erfinden dieses und jenes;

Wenig Gutes ist in der Gemeine, und wirklich verdienen

Wenige darunter auch gute, gerechte Herren zu haben.

$[\ldots]$

Doch das Schlimmste find' ich den Dünkel des irrigen Wahnes,

Der die Menschen ergreift: es könne jeder im Taumel

Seines heftigen Wollens die Welt beherrschen und richten.

Hielte doch jeder sein Weib und seine Kinder in Ordnung,

Wüsste sein trotzig Gesinde zu bändigen, könnte sich stille,

Wenn die Toren verschwenden, in mäßigem Leben erfreuen.

Aber wie sollte die Welt sich verbessern? Es lässt sich ein jeder

Alles zu und will mit Gewalt die andern bezwingen.

Und so sinken wir tiefer und immer tiefer ins Arge. (8, V. 143-16o)

Kern der Geschichte ist eine große Gerichtsverhandlung, in der seine tierischen Mitbürger Reineke Raub, Mord, Betrug und Vergewaltigung vorwerfen - also Kapitalverbrechen - und die spätestens mit Reinekes Freispruch zur Farce gerät. Anders als in den mittelalterlichen Histori ist Goethes Fuchs allerdings kein symbolhafter Bösewicht mehr, sondern ein "Schelm“ (1, V. 14), dessen Intelligenz, List und Redegewandtheit ihm die Sympathien des Lesers einbringen. Am Unglück seiner Opfer trägt er durchaus Mitschuld, in erster Linie versteht er sich aber darauf, deren eigene Dummheit und Habsucht zu seinen Gunsten zu nutzen. Verhandelt wird die ganze Sache am Hoftag des Königs, vor dessen Richterstuhl, was ihr den Rang einer offiziellen Staatsangelegenheit gibt. Damit wird die Nachdichtung endgültig auf die Ebene einer höchst brisanten, staatskritischen Politsatire gehoben, die nicht nur die französischen Verhältnisse vor und während der Revolution mit ätzender Kritik eindeckt, 
sondern die ganze zeitgenössische Machtpolitik - sprich die ganze öffentlichpolitische Welt der Epochenschwelle. Dass Goethes Text, der auf die Zeitgenossen noch wenig Eindruck gemacht hatte, ${ }^{120}$ im vormärzlichen Bayern dann ebenso staatlich behindert wird wie bereits seine Vorgänger ${ }^{121}$, belegt dessen zeit- und gesellschaftskritische Durchschlagskraft.

Obwohl Goethe sich „von der Betrachtung der Welthändel abzuziehen [und] zu zerstreuen"122 suchte, kann von einer eigentlichen Abkehr von den politischen Wirren aber bei weitem nicht die Rede sein. Wenn Goethe die eigene Gegenwart vor Gericht zieht, ist das kein göttliches, sondern ein menschliches bzw. sogar ein tierisches Gericht. Die geistlich-religiöse Sphäre, die bei den früheren Epos-Projekten noch den maßgeblichen Überbau lieferte, wird jetzt konsequent durch eine rein weltliche, machtpolitisch bestimmte Erfahrungssphäre ersetzt, die geprägt ist von Unverhältnismässigkeit, Gier und Übereilung. Die in den frühen Aneignungsversuchen bereits implizierte Ausrichtung des Epischen auf eine kritische Betrachtung des moralischen und politischen Zustands der modernen Erfahrungswelt erfährt damit eine eindeutige Radikalisierung. Mehr noch offenbart sich Goethe bei der Bearbeitung des Reineke Fuchs gerade das besondere Potenzial des Epischen, den festgestellten Krisenphänomenen produktiv zu begegnen, anstatt sie zu sublimieren: Das bedrängende Chaos der Revolution aus Gewalt, Überstürzung und Auflösung wird erzählerisch gebannt und überwunden, indem es satirisch auf Distanz gebracht wird. Die sich vor dem Hintergrund der Terrorjahre bereits zu diesem Zeitpunkt akzentuierenden Schattenseiten von Aufklärung und Säkularisierung - Diskontinuität, Pluralität, Brüche und Widersprüche - rücken nun immer mehr in den Vordergrund ${ }^{123}$ und bilden den historischen Rahmen für die verstärkten Bemühungen um das Epos.

120 Angesicht des realen Terrors sind die meisten Zeitgenossen weder an literarischen Brandreden noch einer kritischen Selbstbespiegelung interessiert. Der Text wird dann auch von der Literaturgeschichte zunehmend marginalisiert und verharmlost. Im 19. Jahrhundert ist Goethes Fuchs als Erziehungstraktat in die Kinderzimmer des Bürgertums verbannt. Derart aus der Erwachsenenlektüre herausgefallen wird der Text zwar nicht mehr ernst genommen, aber weiterhin ökonomisch nutzbar gemacht, vgl. dazu FA 8. S. $1149 \mathrm{f}$.

121 Vgl. Scheffler, Christian: Die deutsche spätmittelalterliche Reineke-Fuchs-Dichtung und ihre Bearbeitung bis in die Neuzeit. In: Rombauts, Edward; Welkenhuysen, Andries (Hrsg.): Aspects of the Medieval Animal Epic (= Mediaevalia Lovaniensia I, III). Leuven: Leuven University Press 1975. S. 85-104, hier S. 94 u. 104.

122 WA I, 33. S. 191 und WA IV, 10. S. 84.

123 Vgl. Pfotenhauer, Helmut: Klassizismus als Anfang der Moderne? Überlegungen zu Karl Philipp Moritz und seiner Ornamenttheorie. In: Flemming, Victoria von; Schütze, Sebastian (Hrsg.): Ars naturam adiuvans. Festschrift für Matthias Winner. Mainz: von Zabern 1996. S. 583-597. 
Unbestritten hat also die Revolutionserfahrung nicht nur eine ganz extreme Wirkung auf Goethe und seine Zeitgenossen, sondern kann durchaus auch als Anlass für die forcierte Epenproduktion betrachtet werden - gerade die Veränderungen im Zeitregime, die im Weiteren noch ausführlich besprochen werden sollen, stehen in unmittelbarem Kontext mit dem Revolutionsereignis und dessen Wahrnehmung im deutschen Kulturraum.

Das Erleben einer wenn auch umfassenden soziopolitischen Krise vermag die Restitution des Epischen um 1800 aber nicht erschöpfend zu erklären. Und vor allem mit Blick auf Reineke Fuchs lässt sich auch die These eines primär durch die Revolution ausgelösten, konservativen Rückfalls auf eine streng normative Gattungspoetik nicht verifizieren. In erster Linie findet nämlich die eigentliche ästhetische Erneuerung der Fuchsdichtung auf der Ebene der Form statt und weist hier vieldeutig auf Goethes eigentümliches Verständnis nicht nur des Epischen, sondern seines übergreifenden Gattungsdenkens überhaupt hin. So integriert und durchformt der Dichter die einzelnen Histori des überlieferten Korpus etwa zu einer einzigen epischen Einheit. Anstatt als lose Sammlung lehrhafter Episoden werden Reinekes Abenteuer nun als ein in sich geschlossenes großes Ganzes mit einem bestimmten Anfang und einem bestimmten Ende dargestellt. Dazu lässt Goethe die von Gottsched noch mitgeführten Glossen, die die Dichtung immer wieder mit lehrhaften Glaubensüberlegungen unterbrechen, weg und erreicht insofern eine gleichzeitige Säkularisierung des Textes. ${ }^{124}$ Anstatt der moralischen Erziehungsfunktion steht nun die Erzählung selbst im Vordergrund. Die durch die Beziehung zwischen Histori und Glosse potenziell vertikale Textorganisation der Vorlagen weicht dadurch einer horizontal fortschreitenden Verknüpfung der Episoden. So entsteht eine durchgehende, fließende Handlung und so können das Fragmentarische und Diskontinuierliche in ein zeitliches Kontinuum überführt werden. Darauf, dass es sich dabei wohl um ein Hauptaugenmerk Goethes gehandelt haben muss, vermögen die zahlreichen und teilweise sehr ausgedehnten Binnenreden zu verweisen, die in der neuen Form zum kontinuierlichen Fortgang der Handlung beitragen: Sowohl im 3. wie auch im 8. Gesang wird die erzählte Zeit der Reise vom Fuchsbau an den Hof durch Reinekes Beichten narrativ verkürzt und gleichzeitig ästhetisiert.

Goethe gliedert die Erzählung neu in zwölf etwa gleichlange Gesänge anstatt in vier sehr unterschiedlich lange Bücher ${ }^{125}$ - die sich wiederum in zwei symmetrische Handlungsteile spalten, was dem Ganzen eine ausgewogene,

124 Vgl. Jäger: Nachwort. In: Goethe: Reineke Fuchs. S. 186.

125 Vgl. ebd. S. 187. 
schöne Proportionalität verleiht. ${ }^{126}$ Unmissverständlich wird damit an die großen Gattungsexemplare des Epos erinnert: an Klopstocks Messias, aber vor allem an die antiken Vorlagen, an die zwölf Gesänge der Aeneis und die jeweils in 24 Gesänge aufgeteilte Ilias und Odyssee von Homer. Goethes Fuchsdichtung ist nicht zuletzt eine Karikatur der Ilias; das machen etwa die Gastfreundschaftsszenen im 3. Gesang deutlich, die zwar klar homerisch inspiriert sind, die bei Homer prägenden Szenen der guten Bewirtung und großen Herzlichkeit inhaltlich aber ins Gegenteil verkehren, wenn Reineke all seinen Gästen übel mitspielt. Weiter wird mit der ganzen Szenerie um den großen Schatz im 10. Gesang, der Rekapitulation des Paris-Urteils (10, V. 79) und Reinekes Auftritt als Hephaistos, die berühmte Beschreibung des Schildes des Achills parodiert. Und auch wenn Reineke am Ende gegen Isegrim kämpft, persifliert Goethe damit den großen Kampf zwischen Achilles und Hektor - der Fuchs ist dem Wolf genauso tödlich überlegen wie der Grieche dem Trojaner, so dass Reineke als strahlender Sieger aus der Konfrontation hervorgeht und sich ganz als Held fühlen kann. ${ }^{127}$

Darüber hinaus markiert Reineke Fuchs auch auf der Ebene der Form eine eindeutige Hinwendung zum homerischen Epos und dessen formalen Besonderheiten als Orientierungs- und Inspirationsquelle für die Versepik der Epochenschwelle. Die derben Knittelverse der mittelalterlichen Vorlage überträgt Goethe nämlich in das Versmaß der antiken Epen und unternimmt damit seine erste eigenständige Hexameterdichtung. ${ }^{28}$ In Verbindung mit einer durchgehenden Verfeinerung des sprachlichen Ausdrucks - anstatt von einer "langbeinigen Hure“129 ist nun von einer "langbeinigen Mähre“ (8, V. 74) die Rede - hebt Goethe den Reineke Fuchs damit zumindest formal auf die Ebene einer anspruchsvollen, kunstreichen Dichtung. Allerdings entspricht seine Versgestaltung kaum der streng regelhaften Metrik der Antike, sondern zeichnet sich gerade durch eine freie, spielerische Verwendung des Hexameters aus, wie sie Klopstock mit seinem Messias vorgestellt hatte. ${ }^{130}$ Der Wechsel der langen und kurzen Silben variiert genau so stark wie die Setzung von Akzenten und Zäsuren, sogar die Fußzahl weicht bisweilen von der metrischen Vorgabe ab. Daraus ergibt sich oft keine schleppende, sondern vielmehr eine beschleunigende Wirkung. Dem satirischen Charakter des Werks

\footnotetext{
126 Vgl. FA I, 8. S. $1146 \mathrm{ff}$.

127 Vgl. FA, I, 8. S. 1137-1139.

128 Vgl. Lee: Eingeleiert in Klopstocks Rhythmik: Der Messias und Goethes Fragment Der ewige Jude. S. 117-131, hier S. 12 .

129 Jäger: Nachwort. In: Goethe: Reineke Fuchs. S. 193.

130 Vgl. Liggieri: Warum gelingt uns das Epische so selten? Ein Blick hinter Goethes Achilleis. S. 158 .
} 
und besonders dem schelmenhaften Fuchscharakter kommt das insofern entgegen, als die Erzählung dadurch einen leichten, beschwingten Klang erhält:

Pfingsten, das liebliche Fest, war gekommen; es grünten und blühten Feld und Wald; auf Hügeln und Höhn, in Büschen und Hecken Übten ein fröhliches Lied die neu ermunterten Vögel; Jede Wiese sprosste von Blumen in duftenden Gründen, Festlich heiter glänzte der Himmel und farbig die Erde. (1, V. 1-4)

In dieser Eingangspassage besteht der erste Vers nur aus Daktylen, während der zweite gleich drei Trochäen enthält, die erste und die zweite sowie die zweite und die dritte Zeile werden mit einem Enjabement verbunden. Diese abwechslungsreiche, dynamische Rhythmik spiegelt zum einen die heitere Freude über die blühende Natur wider und nähert den Text zum anderen dem Lesefluss der Prosa an. Darin zeichnet sich nun bereits ab, dass Goethe hier nicht einer normativen Nachahmungsprogrammatik folgt, wie sie für diese Epochenphase gemeinhin als kennzeichnend gilt, sondern vielmehr nach einem zeitgemäßen Umgang mit der alten Form des Epos sucht. Es sind gerade diese von den Zeitgenossen unterschiedlich aufgenommenen ${ }^{131}$ stilistischen Freiheiten, die Goethe auf neuen Ausdrucksmöglichkeiten des Epischen hinführen und so entschieden zur modernespezifischen Erneuerung der Gattung beitragen: Die alte Fuchsgeschichte wird nicht antik, aber nach antiker Art neu gefasst - nicht nur erlangt sie dadurch neue Relevanz für die aktuelle Zeit, darüber hinaus führt sie auch vor, wie das Epische in der Gegenwart noch einmal gelingen kann.

Wenn Goethe antike Metrik und moderne Prosodie zu regelwidrigen Versen zusammenführt, verweist das nicht auf fehlende Kunstfertigkeit, sondern lenkt den Blick gezielt auf die Form und erzeugt hier ein äußerst reizvolles Spannungsverhältnis zwischen entgegengesetzten Referenzen und Verfahrensweisen. Überhaupt zeigt sich hier das bewusste in Beziehung setzen von Diskrepanzen als eine ästhetische Leitidee Goethes, die dem Epischen besonders zuträglich ist. In Reineke Fuchs trifft der derb-triviale Stoff einer mittelalterlichen, volkstümlichen Tierfabel auf die erhaben-gravitätische Form des antiken Epos: Scharfe Zeitkritik steht neben schwankhaftem Witz, ernsthafte Mahnung neben ironischer Distanzierung. In der Schlussdidaxe lässt sich dieses reibungserzeugende Spiel eindrucksvoll nachvollziehen:

131 Knebel lobt Goethes Verse und auch Herder ist äußerst angetan von Goethes Hexametern, dagegen plädieren Voß und Humboldt für eine festere Form, vgl. ebd. S. $15^{8}$. 
Hochgeehrt ist Reineke nun! Zur Weisheit bekehre

Bald sich jeder und meide das Böse, verehre die Tugend!

Dieses ist der Sinn des Gesangs, in welchem der Dichter

Fabel und Weisheit gemischt, damit ihr das Böse vom Guten

Sondern möget, und schätzen die Weisheit, damit auch die Käufer

Dieses Buch vom Laufe der Welt sich täglich belehren.

Denn so ist es beschaffen, so wird es bleiben, und also

Endigt sich unser Gedicht von Reinekens Wesens und Taten.

Uns verhelfe der Herr zur ewigen Herrlichkeit! Amen. (12, V. 373-381)

Bereits die früheren Epenversuche haben auf ein sensibles Zeitbewusstsein Goethes hingedeutet und an Reineke Fuchs zeigt sich das nun erstmals in seiner ganzen Tragweite. Anstatt als radikalen Revolutionsgegner und konservativen Restaurator weist Reineke Fuchs Goethe als kritisch denkend, reform- und moderneorientiert aus. Zeigt sich daran doch, dass die Reinhaltung der Form für Goethe schon in den frühen 179oer Jahren mehr theoretische Folie als dogmatisches Gebot ist für eine Produktivität, die tatsächlich von formaler Beweglichkeit und Vielfältigkeit profitiert.

Nach diesen überblicksartigen Ausführungen zu den Voraussetzungen und Vorläufen gilt es für die weitere engere Beschäftigung mit der Eposdebatte um 1800 sowie der besonderen Rolle, die Goethe darin einnimmt, Folgendes festzuhalten: Zum einen verbindet Winckelmann das Epos und Homer zum dominanten Komplex der spezifisch deutschen Antikenrezeption, in dem sich bereits die epischen Potenziale und Funktionen ankündigen, die in späteren Gattungsdiskussionen nutzbar gemacht werden. Aber erst Wolfs kritische Philologie macht das homerische Epos produktiv für die deutsche Versepik. Obwohl die vorliegende Arbeit die Verhältnisse ästhetischer Programme gerade nicht als lineare Abfolge begreift, wird hier deutlich, inwiefern am veränderten Umgang mit der Antike die programmatischen Unterschiede zwischen einer eher frühen, stark normativ ausgerichteten und einer späteren, bereits im Kontext von Historizität stehenden Phase des Klassizismus ablesbar werden. Die Historisierung und Philologisierung der Autorperson Homer und dem ihm zugeschriebenen Werk erweisen sich bis hierhin als wichtige Voraussetzung für die modernespezifische Erneuerung des Epischen. Wie im Weiteren nachverfolgt werden soll, können die von Wolf freigesetzten, diskursiven Verschiebungen innerhalb der Eposdebatte als Verweise auf einen sensiblen und selbstkritischen Klassizismus der Jahrhundertwende gelesen werden.

Zum anderen führt Goethe über seine kritischen Auseinandersetzungen mit den großen Gattungsexemplaren der Gegenwartsliteratur bereits vor Wolf einen impliziten Gattungsdiskurs um das Epos, seine Verfahrensweisen 
und Funktionen. Mit seiner spielerischen Herangehensweise an und über die vermeintlich gültigen Grenzen der Gattung hinaus stößt er schon früh auf eine der epischen Form eingeschriebene Flexibilität. Seine antithetischen, fragmentarischen Projekte erweisen sich dabei als experimentelle Flächen, die das Ausprobieren und Neuarrangieren von inhaltlichen und formalen, traditionellen und zeitgenössischen Gattungsmerkmalen ermöglichen. Dass dabei eine kritische Zeitdiagnose und folglich das Anpassen an die Bedingungen und Forderungen der Gegenwart eine - wenn nicht die - zentrale Rolle spielen, wird dann gerade an Reineke Fuchs besonders deutlich, zeigt sich das Werk doch als erster abgeschlossener Versuch Goethes, Fragen der Zeitlichkeit auf die Ebene der Form zu übertragen. 